\title{
El trabajo remunerado de la mujer en el siglo XVIII. Los casos de los contratos femeninos en la industria textil de Andalucía (España) de Laujar de Andarax (Almería) y Úbeda (Jaén) ${ }^{1}$
}

\author{
The paid work of women in the eighteenth century. The cases of female contracts in the textile industry of Andalusia \\ (Spain) of Laujar de Andarax (Almería) and Úbeda (Jaén))
}

\author{
Luis Garrido-González \\ Departamento de Economía. Area de Historia e Instituciones Económicas. \\ Universidad de Jaén, España \\ lgarrido@ujaen.es
}

\section{ReSUMEN:}

El objetivo principal que se plantea es el estudio del trabajo femenino en la industria textil de Andalucía (España). Para ello, en primer lugar, se analizan los tipos de contratos laborales, tanto formales como informales o explícitos por los que se regulaba el trabajo en la industria textil de lana, seda y lino en la Andalucía del siglo XVIII. Se utiliza la información de las respuestas particulares o memoriales del Catastro de Ensenada (1751-52) correspondientes a Laujar de Andarax (Almería) y Úbeda (Jaén). A continuación, se comparan dichos contratos con los que se establecían en la agricultura, ganadería y el sector servicios de esas mismas localidades. Finalmente, se analizan las diferencias que existían en los contratos laborales femeninos respecto a los masculinos. En esta aportación, tras la introducción se aborda el contexto socio-económico de las localidades analizadas, la actividad textil desarrollada en ellas dentro del entorno andaluz de mediados del siglo xviii, para terminar con el estudio de los contratos formales y los acuerdos informales de trabajo y las rentas anuales que se obtenían en la manufactura textil en comparación con las restantes actividades laborales de mujeres y hombres. Se termina con las correspondientes conclusiones.

Palabras Clave: Desigualdad, Mercado laboral femenino, Contratos, Trabajo, Rentas, Andalucía, Siglo XVIII.

\section{ABSTRACT:}

The leading objective is the study of female work in the textile industry of Andalusia (Spain). In order to do this, first, we analyse the types of labor contracts, both formal and informal or explicit by regulating work in the textile industry of wool, silk and linen in Andalusia of the eighteenth century. The information of the particular answers or memorials of the Cadastre of Ensenada (1751-52) corresponding to Laujar de Andarax (Almería) and Úbeda (Jaén) is used. Then, these contracts are compared with those established in agriculture, livestock and the services sector of those same localities. Finally, the differences that existed in female labor contracts with respect to males ones are analysed. In this contribution, after the introduction it deals with the socioeconomic context of the analyzed localities, the textile activity developed in them within the Andalusian environment of the mideighteenth century, to end the study of formal contracts and informal work agreements and annual incomes obtained in textile manufacturing compared to the other labor activities of women and men. It ends with the corresponding conclusions.

KEYWORDS: Inequality, Female labor market, Contracts, Work, Income, Andalusia, 18th century.

\section{INTRODUCCIÓN}

Existen estudios que demuestran una abundante actividad laboral femenina remunerada durante todo el año, tanto el siglo XVIII como en el XIX en Europa y América entre las clases populares ${ }^{2}$. En cambio, entre las élites, el papel de la mujer se limitaba a ser un elemento más de la negociación vía matrimonial (Arias, 2017, 2018; Bartolomé y Pérez Álvarez, 1999; García González, F., 1999, 2004, 2008, 2011; Jaciuk, 2017; López-Cordón y Carbonell-Esteller, 1997; Martín García y Pérez Álvarez, 1997, 2014, 2016; Rey-Castelao, 2018), aunque hay que señalar el importante papel económico de las mujeres en los conventos de monjas (Rey-Castelao, 2009b, 2012a; García González, 1996).

Recepción: 20 de diciembre de 2018 | Aprobación: 28 de marzo de 2019 | Publicación: 12 de julio de 2019 
Las relaciones laborales contractuales del siglo XVIII fueron reguladas por el Estado, dentro de la legislación reformista borbónica, que confirió a la mano de obra femenina un papel esencial para su proyecto industrial. La política manufacturera ilustrada facilitó el empleo femenino en las Fábricas Reales y las privilegiadas, sirviéndose de la tradicional industria rural dispersa en la que trabajaban numerosas mujeres. ${ }^{3}$ Gracias a los decretos del Estado, las Fábricas Reales, las Juntas Locales de comercio, las Sociedades Económicas de Amigos del País o las Diputaciones, se extendieron diversas medidas asistenciales y educativas a favor de niñas y mujeres para la formación de ese nuevo mercado laboral. Los argumentos de su escasa cualificación o su falta de formación en capital humano del trabajo femenino, trataron de justificar los bajos salarios y la asignación de tareas consideradas de menor estatus. Para ello, se desarrolló una acelerada labor legislativa, se facilitó la reconversión industrial promoviendo la iniciativa privada y descentralizando el modelo de Reales Fábricas y se intentó implantar una formación de la mano de obra industrial, saltándose los monopolios gremiales vigentes.

Así el Estado aplicó una política de empleo que pasaba por la incorporación de la mano de obra femenina e infantil, que era además la más barata. Fuera del período que estudiamos aquí, evidentemente, la reforma legislativa, culminó en el Real Decreto de 1784 que derogaba las normas que imposibilitaban el trabajo de las mujeres en las manufacturas. Aparentemente dicha ley, que en realidad había sido anticipada por otra de menor amplitud en 1779, concedió plena libertad al empleo de trabajadoras en las industrias, abriendo la entrada a una amplia integración de las mujeres en el mercado laboral; pero, en última instancia, su cumplimiento dependía de la voluntad de las autoridades locales.

En los casos estudiados para Andalucía el trabajo femenino se contrataba a cambio de unas remuneraciones salariales en metálico y en el pago en especie u otras contraprestaciones como el vestido, la vivienda y el aprendizaje del que se beneficiaban quienes prestaban su esfuerzo laboral. Las remuneraciones anuales o por jornadas realizadas se basaban en el destajo, el trabajo por objetivos y en la pluriactividad que permitían diversificar riesgos y los tipos de rentas percibidas a lo largo del año.

Las fuentes que se utilizan son los memoriales, relaciones o respuestas particulares del Catastro de Ensenada (1751-52), correspondientes a Laujar de Andarax, en la provincia de Almería, ${ }^{4}$ y a Úbeda en la provincia de Jaén. ${ }^{5}$ A diferencia de las Respuestas Generales (RG), que son meros resúmenes, se trata de una fuente excepcional por la minuciosa información que contiene sobre cada familia y su situación social y económica: edades, estado civil, ocupaciones, profesiones, salarios, propiedades rústicas y urbanas, rentas, deudas, etc. Pero su tratamiento requiere un esfuerzo descomunal, ya que tras su transcripción se debe ordenar y elaborar las bases de datos de una enorme complejidad, dados los cruces y redes personales, familiares y vecinales que se detectan, para que la hagan comprensible y se puedan extraer las correspondientes interpretaciones.

Desde el punto de vista metodológico se adopta una definición de trato laboral como aquel que conlleva una actividad remunerada en especie o en dinero y que supone un trabajo a jornada o a destajo. No se incluye ningún tipo de acuerdo oral dentro del entorno familiar sobre el reparto de tareas para su propio consumo, que por supuesto es trabajo productivo y que seguramente realizaban todas las niñas o numerosos niños y algunas ancianas y ancianos, como cuidar de niños pequeños, traer agua o leña, hacer recados, barrer o fregar en sus casas, trabajar en la tierra y vigilar el ganado o los animales de corral que tuviera la familia.

Se señalan los tratos que acordaban las rentas anuales para los oficios y clasificaciones laborales literales que aparecen en los memoriales del Catastro de Ensenada. Aunque en el presente trabajo no se ha incluido cuando se dispone de la información, se pueden recoger datos de salarios diarios y de los pagos en especie. Y en los casos de pluriactividad que suponían contratos diferentes se pueden distinguir los ingresos correspondientes a cada trabajo.

Otras cuestiones metodológicas importantes que se plantean son las relacionadas con la existencia de una importante pluriactividad; sobre la que es necesario tener en cuenta los diferentes arreglos que hubiera entre las partes. Eran más importantes en Úbeda que en Laujar, ya que las mujeres de la primera localidad 
tenían contratos como hilanderas, pero también llegaban a acuerdos para trabajar como criadas en las casas y, a tiempo parcial, se dedicaban a las actividades textiles, cuya remuneración percibía su padre, madre o la persona para quien trabajaban. Los ajustes de los sirvientes se basaban en ser mantenidos en la casa de quienes les contrataban, trabajando a cambio de la comida, alojamiento y vestido, en especial en el caso de niños y mujeres. Por ese motivo a veces no se hace constar en las fuentes las rentas percibidas. Pero se puede establecer el valor monetario de dicho trabajo. Esto se ha hecho directamente porque se declara, y además en las fuentes se corrige al alza en caso de que esté infravalorado en el memorial. Otro método de aproximación al valor monetario del trabajo es calculando indirectamente el ahorro que suponía hacerlo exclusivamente con los integrantes de la familia, de la que formaban parte las criadas y criados. Cuando no se registra el salario en las fuentes por el trabajo que realizaban los adultos integrantes de la familia ni de los sirvientes, se ha considerado el valor monetario a precios corrientes del trabajo que sí declaraban en otros casos. Esta decisión metodológica viene justificada porque está sobradamente admitido en la literatura que se debe imputar un gasto directo para la familia, cuando se tiene que contratar mano de obra ajena, al externalizar las labores que los miembros de la misma y sus sirvientes no realizan.

En este sentido, es necesario situar los tratos de trabajo femenino de mediados del siglo XVIII en relación al debate historiográfico del trabajo femenino preindustrial, que ha adquirido un gran interés en la historiografía actual (Benaul, 1995; Birriel, 2008a, 2015b, 2016c; Blasco, 2017; Borderías y Gálvez, 2014; Parejo, 1987). Para ello es imprescindible explicitar las diferencias del trabajo femenino antes y después de la industrialización. Como han puesto de manifiesto los estudios historiográficos centrados en el trabajo femenino durante las primeras etapas de la Revolución Industrial, existe una gran confusión sobre el mismo, tanto fuera como dentro del hogar. ${ }^{6}$ Por tanto, la investigación sobre el trabajo de las mujeres se ha encontrado limitada por la escasez de fuentes históricas al respecto. En particular, la no disponibilidad de registros censales para el empleo femenino y los defectos que plantean las fuentes censales para el siglo XVIII, e incluso el XIX, hace difícil tener una idea exacta del empleo femenino. Este hecho hizo pensar que no iba a ser posible aclarar si la industrialización mejoró el empleo femenino, como afirmaba la historia económica tradicional, o perdieron sus trabajos muchas mujeres (Thomas, 1988. Mayordomo 2000).

En los últimos años la historia del trabajo de las mujeres durante el XIX ha tenido avances considerables. Se han aplicado nuevas técnicas al análisis de los datos existentes ya que, como han demostrado Horrell y Humphries (1995), Humphries y Sarasúa (2012), Humphries y Weisdorf (2014), los estudios históricos sobre ocupaciones particulares y oficios, han aportado una rica y más completa información al respecto. Se ha alcanzado una primera aproximación a la participación laboral de las mujeres, que durante esta etapa (1750-1840) disfrutaron de estabilidad laboral y unas tasas de participación relativamente elevadas. A partir de la expansión de la industrialización sí se produjo un descenso en la actividad femenina (1840-1900). Pero el inconveniente principal de los datos agregados es que no reflejan las características particulares que tenían los empleos femeninos, ni las diferencias que existían entre los acuerdos o tratos laborales con las mujeres y los hombres (Borderías y Carrasco, 1994). Las investigaciones historiográficas centradas en estudios de casos particulares, demuestran que el impacto de la industrialización sobre el empleo femenino y los contratos o acuerdos laborales correspondientes fueron más heterogéneos y menos desastrosos de lo que afirmaba la historiografía tradicional. Los puestos de trabajo ofertados eran limitados y estaban fuertemente segregados, la mayoría de ellos estaban destinados a mujeres jóvenes y solteras y normalmente en sectores como las manufacturas familiares características de la protoindustria o putting-out-system, los pequeños talleres, el comercio y los servicios domésticos (Tilly y Scott, 1989). Las mujeres, cuyos ingresos habían sido vitales en el siglo XVIII para asegurar la reproducción de la familia, fueron las trabajadoras protoindustriales típicas, de tal manera que puede decirse que con las primeras fábricas no cambiaron las tareas que realizaban. Lo que sí sucedió es que hubo un cambio cualitativo, pero que afectó también a los hombres: la proletarización transformó la organización, el ritmo y la disciplina laboral de las ocupaciones femeninas y masculinas. En las nuevas industrias textiles capitalistas las mujeres pasaron a fabricar las manufacturas que antes hacían 
en su familia bajo el sistema doméstico. Pero a diferencia de los hombres, las mujeres encontraron mayores dificultades para simultanear las tareas y tiempos de la producción de mercancías, con el trabajo doméstico no remunerado que normalmente desempeñaban.

Por otra parte, es necesario destacar la importancia para el empleo femenino que las manufacturas familiares continuaron teniendo en el XIX, tanto como lo habían tenido durante el siglo XVIII. Muchas de las ocupadas en el sector secundario trabajaban en la industria textil, y la cuantía de empleadas en las manufacturas familiares de prendas de vestir siguió siendo elevada durante la industrialización(Tilly y Scott, 1989). El empleo industrial tradicional fue habitual durante gran parte del siglo XIX, aunque poco a poco el trabajo en el taller familiar se fue reemplazando por el trabajo a destajo, y continuó utilizando a muchas mujeres que cosían y remendaban en sus casas por un salario inferior al que se pagaba en las fábricas. La industria de prendas de vestir se mecanizó lentamente, al poder contar con una abundante mano de obra femenina barata, que permitía mantener el sistema del putting-out-system. Según Tilly y Scott (1989), incluso en Inglaterra, las fábricas textiles surgieron después de 1850 y la forma tradicional de la producción textil continuó hasta principios del siglo XX. En el caso español, este tipo de empleo femenino se ha sostenido hasta finales de ese siglo, aunque dada su tipología "sumergida", las mujeres que trabajan en el mismo son difíciles de cuantificar (Mayordomo, 2000). En resumen, si bien con la industrialización emergieron nuevas oportunidades de empleo en las modernas fábricas, también aumentaron las mujeres empleadas en el sector textil tradicional.

Otro sector en el que se creó mucho empleo femenino fue el de servicios. Pero, realmente, con la industrialización durante la primera mitad del siglo XIX estuvo más vinculado a la expansión de las sirvientas domésticas que a la creación de puestos de trabajo modernos. Sólo a finales del siglo XIX, muchas mujeres entraron a trabajar en profesiones del sector terciario como oficinistas, maestras o dependientas de tiendas y almacenes; lo cual hizo que aumentara la cantidad de mujeres empleadas. Pero estas nuevas oportunidades no supusieron un incremento espectacular del empleo femenino. Como indican Tilly y Scott (1989), los niveles de empleo de principios del XIX no se recuperaron en Inglaterra hasta mediados del XX. En este período, el servicio doméstico fue la ocupación más frecuente para jóvenes solteras. Un tipo de empleo que creció conforme las clases medias urbanas se expandieron.

Finalmente, cabe señalar que entre los objetivos que se plantean en esta aportación, en primer lugar, se ha tratado de estudiar el tipo de contratos laborales por los que se regulaba el trabajo en la industria textil de lana, seda y lino en la Andalucía del siglo XVIII. En segundo lugar, se ha considerado que para ello el mejor método era utilizar la información de casos concretos, basados en las interesantes respuestas particulares o memoriales del Catastro de Ensenada (1751-52) sobre Laujar de Andarax (Almería) y Úbeda (Jaén). En tercer lugar, se comparan dichos contratos con los que se establecían en la agricultura, ganadería y el sector servicios de esas mismas localidades. Finalmente, se analizan las diferencias que existían en los tratos laborales de las mujeres respecto a los hombres. El trabajo se presenta con la estructura siguiente: tras la introducción, se aborda el contexto socio-económico de las localidades analizadas, la actividad textil desarrollada en ellas dentro del entorno andaluz de mediados del siglo xviii, para terminar con el estudio de los tratos y acuerdos de trabajo y las rentas anuales que se establecían en la manufactura textil en comparación con las restantes actividades laborales de mujeres y hombres. Se finaliza con las correspondientes conclusiones.

\section{ConteXto SOcio-Económico}

La villa de Laujar de Andarax se localiza al oeste de la provincia de Almería en la misma frontera con la de Granada, y forma parte de la comarca de la Alpujarra, que está situada al sur de Sierra Nevada (Puertas, 1991, p. 17). Como se ve en la tabla 1, la población prosperó y sus habitantes casi se duplicaron en la segunda mitad del siglo XVIII. Posteriormente, entró en una clara decadencia hasta mediados del siglo XIX, experimentando una pérdida de población del $16 \%$. 
Úbeda era en el siglo XVIII una ciudad de realengo (Porras, 1984, p. 802), que daba nombre a la comarca de La Loma. Su prosperidad se había debido a que era centro de un cruce de caminos entre Levante, el interior de la Meseta castellana y Andalucía occidental, siguiendo el curso natural de los puertos de montaña, los valles y los ríos.

Pero durante el siglo XIX no mejoraron los caminos naturales (Garrido, 1996), siendo una de las causas que justificaría un lento crecimiento en la primera mitad de la centuria decimonónica (Tarifa, 1999, pp. 5-6). Así se comprueba con los datos de población recogidos en la tabla 1. Entre 1752 y 1787, prácticamente permaneció estancado su peso demográfico en el conjunto provincial.

TABLA 1

Evolución de la población Laujar de Andarax (1751-1842) y Úbeda (1752-1842)

\begin{tabular}{|l|c|c|c|}
\hline & $\mathbf{1 7 5 1 - 5 2}$ & $\mathbf{1 7 8 7}$ & $\mathbf{1 8 4 2}$ \\
\hline Provincia Almeria & 124.362 & 161.963 & 252.952 \\
\hline Tasa crecimiento anual acumulativo & - & 0,76 & 0,81 \\
\hline Laujar de Andarax & 2.277 & 4.118 & 3.454 \\
\hline Tasa crecimiento anual acumulativo & - & 1,71 & $-0,32$ \\
\hline \% Luaiar/Almeria & 1,8 & 2,5 & 1,4 \\
\hline Provincia Jaén & 188.193 & 193.986 & 246.558 \\
\hline Tasa crecimiento anual acumulativo & - & 0,09 & 0,44 \\
\hline Población Úbeda & 9.916 & 11.145 & 13.086 \\
\hline Tasa crecimiento anual acumulativo & - & 0,33 & 0,29 \\
\hline \% Úbeda/Jaén & 5,3 & 5,7 & 5,3 \\
\hline
\end{tabular}

Fuente: Catastro de Ensenada. Vecindario y libro producible de eclesiásticos y seculares de Laujar de Andarax, 1751 (AHP Almería). Catastro de Ensenada. Respuestas Generales de Laujar de Andarax, 1751 (Portal de Archivos Españoles). Catastro de Ensenada. Libros memoriales y personal de legos y eclesiásticos de Úbeda, 1752 (AHP Jaén). Catastro de Ensenada. Respuestas Generales de Úbeda, 1752 (Portal de Archivos Españoles). Censo de Floridablanca, 1787. Matrícula catastral, 1842. Madoz (1850a, p. 161) y (1850b, p. 241).

El Catastro de Ensenada (1751-52) proporciona la información más completa que tenemos sobre el trabajo femenino para la Corona de Castilla. Lo fundamental es que dicha fuente registra las ocupaciones de las mujeres. Algo que ocurre en muy pocos $\operatorname{casos}^{8}$.

La economía de las dos localidades estudiadas estaba basada en la manufactura textil, la agricultura y la ganadería. Respecto a la primera le corresponderían las características de la llamada "protoindustrialización”, y más recientemente revolución industriosa. ${ }^{9}$ Se trataba de una industria doméstica, no agremiada, realizada a tiempo parcial y de carácter estacional. A mediados del XVIII había adquirido una condición marginal y se basaba en la elaboración de géneros de baja calidad de lana, lino y seda, destinados al autoconsumo o a un mercado cercano de tipo local o comarcal. ${ }^{10}$ De cualquier forma, se trataba de un trabajo a tiempo parcial, doméstico, muy apropiado para el hilado y tisaje de la lana y especialmente del lino, que es una fibra muy adecuada por sus características de ductilidad y bajo rendimiento a la producción familiar y a las condiciones de mano de obra femenina e infantil. En relación a la agricultura, las mayores cosechas eran de trigo, aunque se producían también en menor cantidad otros cereales, leguminosas, aceite, vino y productos de huerta. Asimismo se cultivan moreras para la producción de seda, tanto en Úbeda como en Laujar, y además lino en esta última. La ganadería era importante para el abastecimiento de lana que consumía la industria textil, al contar Úbeda con 22.000 ovejas y Laujar con 4.730. También existían en las dos localidades manufacturas de 
productos agroalimentarios, como "hornos de pan cocer", molinos harineros y almazaras para la producción de aceite, aunque en Laujar estas últimas no aparecen al ser poco importante la plantación de olivar.

La actividad textil se realizaba a domicilio por tejedores y mujeres hilanderas de lana. En Laujar también funcionaba desde 1712 "una fábrica de paños que se llevó de Alcoy" (Puertas, 1991, pp. 107, 125), y según las Repuestas Generales (RG) había 4 batanes de paño, "y tambien ay diferentes texedores y texedoras de Lienzo que llaman tiradizo para el abasto de las casas". Exactamente 10 -2 hombres y 8 mujeres-, de los cuales los hombres y una de las mujeres trabajaban con dos telares y las restantes con uno. Además existían "doscientos y cinquenta y seis tornos de hilar lana para las fábricas de dichos paños”, donde se producían tintes, paños y bayetas. Esta actividad textil daba trabajo a cardadores de lanas, hombres y mujeres hilanderas, tejedores, tintoreros, tundidores y canilleros. Otro trabajo textil especializado de hombres y mujeres era la preparación e hilado de seda, de carácter estacional, pero que les permitía complementar la temporada local de trabajo en otros lugares más o menos cercanos, porque según las RG:

"hay número de hilanderos [e hilanderas] de seda que hilan dicha especie asi en esta villa como en otros pueblos de este partido, y en expecial en el reyno de Murcia, a donde ban primeramente a hilar por ser allí más temprana esta cosecha, y después prosiguen en este partido".

La industria sedera proporcionaba a las mujeres de Laujar una ocupación que, en su temporada alta, les llevaban bastantes horas de trabajo diario, debido a que se encargaban de la cría del gusano de seda: recogida de las hojas del árbol moral, limpieza de las seras -espuertas grandes- donde estaban los gusanos, les suministraban su alimento y otras tareas antes del hilado. En realidad, constituían una verdadera industria familiar muy feminizada.

También había una actividad industrial complementaria a la manufactura textil, que daba trabajo a tintoreros, cardadores, monteros, sastres y cordoneros. En el siglo XVIII, el comercio al por mayor de Laujar estaba muy relacionado con la producción textil, al consistir en la venta de paños e indianas. En cambio, desde Úbeda no sólo se comercializaban tejidos de lana, lino, encajes, hilo de lana y cáñamo, sino que también era importante la distribución al por mayor de aceite, cereales y vino.

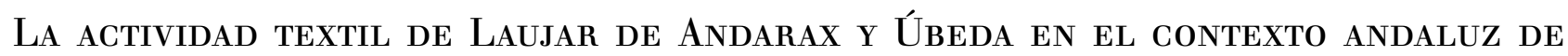 MEDIADOS DEL SIGLO XVIII}

En 1750 el sector lanero andaluz había iniciado su decadencia (Parejo, 1987, p. 65). En el territorio que se integraba en el antiguo Reino de Sevilla los núcleos más importantes de la industria de la lana se situaban en Écija, Carmona, Marchena, Tocina, Lebrija, Fuente de Andalucía, Cantillana, Alcalá de Guadaira, San Juan de Aznalfarache, Osuna, Estepa, Campillos, Antequera, ${ }^{11}$ Archidona y la ciudad de Sevilla. Se basaba en un tipo de pañería no especializada que producía paños de mediana e inferior calidad que se consumían en la propia ciudad y su zona rural del entorno, aunque todavía se abastecía algo el mercado regional, nacional e incluso ultramarino conectado con los puertos andaluces de salida (Parejo, 1987, pp. 67-72). En todas esas localidades era fundamental el trabajo de las hilanderas, aunque no esté registrado en las fuentes. Así lo demuestra el funcionamiento de una escuela de hilar estambre para enseñar gratuitamente a mujeres y niñas, que se puso en marcha en la fábrica de Sevilla para la producción de bayetas. Fue instalada en 1779 por el comerciante sevillano Antonio Arboré. Éste intentaba disponer de una mano de obra femenina especializada, pero más barata que la masculina. En dicha fábrica aprendieron a hilar 150 mujeres y niñas hasta 1781. De hecho, en este último año la plantilla de 686 personas estaba claramente feminizada, con un 89\% de mujeres empleadas frente a un $11 \%$ de hombres. Estaba integrada por 450 hilanderas de estambre, 120 hilanderas de trama, 25 desmotadoras, 6 enrodeladoras, 2 urdidoras, 9 despinzadoras, 6 cardadores, 6 peinadores, 42 tejedores, 10 bataneros y 10 tintoreros-prensadores (Parejo, 1987, p. 70) 
En Córdoba, la pañería lanera tradicional se concentraba en el valle de Los Pedroches, extendiéndose hacia el oeste hasta Sierra Morena y la Campiña donde se encontraban focos pañeros importantes como Pozoblanco, Bujalance, Fernán Núñez, Aldea del Rio y Aguilar de la Frontera, pero que tenía una producción cada vez más localizada y limitada (Parejo, 1987, pp. 73-78).

En el conjunto Jaén la situación de la industria de la lana no era mejor. Habían entrado en decadencia los principales centros pañeros como la ciudad de Jaén, Baeza y Úbeda. No fueron capaces de adaptarse a las nuevas realidades del mercado surgidas a mediados del XVIII, por lo que restringieron la producción y su área de comercialización. Como veremos para 1752, muchas de las mujeres mayores de 50, 60 y más años de Úbeda se calificaban como hilanderas, porque era la profesión que habían tenido desde su juventud, treinta o cuarenta años atrás. Según el Catastro de Ensenada, había 14 tejedores, 21 cardadores y 2 batanes con 40 telares de paños activos, pero en 1782, apenas quedaban 10 telares funcionando y escaseaba la mano de obra femenina y masculina especializada. En la ciudad de Jaén, el Catastro de Ensenada registraba 35 cardadores, 94 tejedores y 10 tintoreros (Parejo, 1987, pp. 78-81).

En el territorio que se integraba en el antiguo Reino de Granada la pañería no tenía tradición, salvo el núcleo importante de Montefrío, estudiado por David y Manuel Martínez (Martínez López y Martínez Martín, 2003), y el de Laujar de Andarax en Almería, que se presenta en este trabajo. En Montefrío, el trabajo como hilanderas se iniciaba en la infancia. Resultaba de gran utilidad para las familias, al permitirles autoabastecerse y completar los ingresos de jornaleros y pegujaleros, que era como se denominaban a los pequeños y medianos propietarios o arrendatarios. Existen indicios de que esta actividad industrial, aunque mal pagada, resultaba vital para la supervivencia de numerosas familias pobres (Martínez López y Martínez Martín, 2003, p. 143)

La industria sedera también estaba en declive a mediado del XVIII. Se localizaba en las ciudades de Granada, Jaén, Málaga, Córdoba, Sevilla, Cádiz, Écija, Priego, Antequera y Puerto de Santa María (Parejo, 1987, pp. 87-108). En los casos estudiados en el presente trabajo, en las fuentes del Catastro de Ensenada sólo se hace referencia a la misma en Laujar, pero no en Úbeda. Sí aparecen más alusiones a las industrias linera y cañamera, sobre todo, en el caso de Úbeda por la presencia de algunas hilanderas de lino y cáñamo. En realidad, era una industria que estaba dispersa por distintas localidades de Sevilla, Córdoba, Jaén y Granada (Parejo, 1987, p. 110).

En el siglo XVIII las mujeres de Laujar de Andarax y Úbeda trabajaban, sobre todo, en la industria textil (hilanderas) y en el servicio doméstico (tablas 2 y 3 ), que es característico del trabajo preindustrial femenino. Posteriormente, en el siglo XIX, cayeron el número de las primeras y se mantuvieron o aumentaron las segundas (Sarasúa, 2007; Campos, 2014). 
TABLA 2

Número de mujeres y hombres de cualquier edad registrados en la industria textil y los servicios domésticos y religiosos Laujar de Andarax (1751)

\begin{tabular}{|c|c|c|c|c|c|}
\hline Ocupaciones & Mujeres & $\%$ & Ocupaciones & Hombres & $\%$ \\
\hline Hilandera & 339 & 66,2 & Labrador & 179 & 27,1 \\
\hline Criada & 63 & 12,3 & Jomalero del campo & 148 & 22,4 \\
\hline Tejedora de lienzo & 4 & 0,8 & Cardador de lana & 65 & 9,8 \\
\hline Tejedora de paños & 4 & 0,8 & Tejedor de patios & 46 & 7,0 \\
\hline Propietaria fábrica de paños & 3 & 0,6 & Eclesiástico & 25 & 3,8 \\
\hline Ama & 2 & 0,4 & Pastor & 25 & 3,8 \\
\hline Cardadora de lana & 1 & 0,2 & Hilandero de seda & 21 & 3,2 \\
\hline Resto de ocrspaciones & 96 & 18,8 & Criado & 18 & 2,7 \\
\hline \multirow[t]{13}{*}{ TOTAI } & 512 & 57,2 & Fabricante de paños & 13 & 2,0 \\
\hline & & & Hortelano & 12 & 1,8 \\
\hline & & & Maestro de la fábrica de paños & 10 & 1,5 \\
\hline & & & Canillero & 8 & 1,2 \\
\hline & & & $\begin{array}{l}\text { Jomalero en fábrica de lanas y en } \\
\text { hilatura de seda }\end{array}$ & 6 & 0,9 \\
\hline & & & Tundidor de paños & 6 & 0,9 \\
\hline & & & Batanero & 4 & 0,6 \\
\hline & & & Tintorero & 4 & 0,6 \\
\hline & & & Sastre & 2 & 0,3 \\
\hline & & & Guarda de seda & 1 & 0,2 \\
\hline & & & Tejedor de lienzo & 1 & 0,2 \\
\hline & & & Resto de ocupaciones & 66 & 10,0 \\
\hline & & & TOTAI & 660 & 84,7 \\
\hline $\begin{array}{l}\text { Mujeres en edad de trabajar } \\
\text { (10-60 años) }\end{array}$ & 895 & 75,3 & $\begin{array}{l}\text { Hombres en edad de trabajar (10- } \\
60 \text { años) }\end{array}$ & 779 & 71,6 \\
\hline Total mujeres & 1.189 & & Total hombres & 1.088 & \\
\hline
\end{tabular}

Fuentes: tabla 1. 
TABLA 3

Número de mujeres y hombres de cualquier edad registrados en el sector agrario, la industria textil y los servicios domésticos y religiosos Úbeda (1752)

\begin{tabular}{|c|c|c|c|c|c|}
\hline $\begin{array}{l}\text { Ocupaciones } \\
\text { Criacla }\end{array}$ & \begin{tabular}{r|} 
Mujeres \\
452 \\
\end{tabular} & $\begin{array}{c}\% \\
31,1\end{array}$ & \begin{tabular}{|l} 
Ocupaciones \\
Jornalero del campo
\end{tabular} & $\begin{array}{r}\text { Hombres } \\
567\end{array}$ & $\begin{array}{c}\% \\
18,5\end{array}$ \\
\hline Hilandera & 183 & 12,6 & Eclesiástico & 376 & 122 \\
\hline Monjas & 156 & 10,7 & Peguxalero & 362 & 11,8 \\
\hline Asistencia doméstica & 93 & 6,4 & Pastor & 267 & 8,7 \\
\hline En a sistencia & 54 & 3,7 & Labrador & 130 & 42 \\
\hline Encompañia & 33 & 2,3 & Cria do & 125 & 4,1 \\
\hline Costuxera & 20 & 1,4 & Mulero & 119 & 39 \\
\hline Teje dora & 18 & 1,2 & Hortelano & 110 & 3,6 \\
\hline Hacer medias & 9 & 0,6 & Sastre & 35 & 1,1 \\
\hline $\mathrm{Am}$ & 6 & 0,4 & Gañán & 27 & 0,9 \\
\hline Espartera & 2 & 0,1 & Carchador de lana & 23 & 0,7 \\
\hline Propietaria fábrica textil & 2 & 0,1 & Aperador & 15 & 0,5 \\
\hline Anm de leche & 1 & 0,1 & Espartero & 8 & 0,3 \\
\hline Comercio lana & 1 & 0,1 & Rastrillador de cáñamo & 6 & 0,2 \\
\hline Cuxar lienzos & 1 & 0,1 & Tejeclor de paños & 6 & 0,2 \\
\hline Hacer encajes & 1 & 0,1 & Tejedor de paños y bayetas & 6 & 0,2 \\
\hline Propietaria tiencla esparteria & 1 & 0,1 & Zurrador & 6 & 02 \\
\hline Tintorera & 1 & 0,1 & Cordonero & 5 & 0,2 \\
\hline Resto de $\propto$ upaciones & 421 & 28,9 & Tintorero & 3 & 0,1 \\
\hline \multirow[t]{4}{*}{ TOTAL } & 1.455 & 32,1 & \begin{tabular}{|l|} 
Batanero \\
T'ejedor de lana
\end{tabular} & $\begin{array}{l}2 \\
2\end{array}$ & $\begin{array}{l}0,1 \\
0,1\end{array}$ \\
\hline & & & Botonero & 1 & 0,0 \\
\hline & & & $\begin{array}{l}\text { Coletero } \\
\text { Sombrerero }\end{array}$ & $\begin{array}{l}1 \\
1\end{array}$ & $\begin{array}{l}0,0 \\
0,0\end{array}$ \\
\hline & & & Resto de $\propto$ upaciones & 869 & 28,3 \\
\hline $\begin{array}{l}\text { Mijueres en edad de trabajar (10-60 } \\
\text { años) }\end{array}$ & 4.530 & 87,3 & $\begin{array}{l}\text { TOTAL } \\
\text { Hombres en eclad de trabajar (10-60 } \\
\text { años) }\end{array}$ & $\begin{array}{l}3.072 \\
3.810\end{array}$ & $\begin{array}{l}80,6 \\
80,6\end{array}$ \\
\hline Total mijeres & 5.191 & & Total hombres & 4.725 & \\
\hline
\end{tabular}

Fuente: tabla 1.

Se han incluido en las tablas 2 y 3 las ocupaciones relacionadas con la actividad textil y con el servicio doméstico de las mujeres de cualquier edad, que aparecen registradas en el Catastro de Ensenada. En Laujar se conocen las ocupaciones de un total de 512 mujeres y en Úbeda de 1.455 mujeres., de las que se registró explícitamente su ocupación, aunque algunas de ellas aparecen con más de una actividad que les resultaba necesaria para completar sus ingresos o porque resultaba alternativa en determinadas épocas del año. Ahora bien, en los anteriores datos sólo se recoge una sola ocupación en cada caso, para evitar duplicidades e incluso triplicidades. La información disponible permite comprobar que las mujeres realizaban simultáneamente 
varias actividades relacionadas con el trabajo textil, como eran la de hilar, hacer media, coser, desmotar lana, hacer encajes, tejer, lavar.

En este punto es necesario aclarar que las anteriores cifras de ocupación no coinciden con los datos de la población activa femenina, porque estos últimos sólo corresponden a la población entre 10 y 60 años. En las anteriores cifras lo que se considera es la ocupación registrada que tienen todas las mujeres, independientemente de su edad.

Las principales ocupaciones por el número de mujeres que las desempeñaban, coincidían en Laujar y Úbeda. Las hilanderas y las criadas ocupaban el primer lugar, respectivamente. En segundo término, aparecen las criadas en Laujar, mientras que las hilanderas lo hacen en Úbeda. En esta última ciudad, incluso aumenta el número de mujeres trabajadoras asimiladas a las criadas, si se suman las que se registran bajo la denominación de "en compañía", cuyo número era de 33, o "en asistencia" que alcanzaba 54 mujeres. Eran tratos a que se llegaba a cambio de una contraprestación en especie o dinero, cuyas características veremos más adelante.

Otro aspecto importante es relacionar el número de hijos u otros parientes en edades no laborales con los distintos grupos de mujeres casadas, viudas y solteras (tabla 4). La razón reside en que eran ellas, sin duda, las que los tenían a su cargo y aunque no recibiesen una remuneración, como sigue sucediendo actualmente en la mayoría de los casos. Pero esa actividad hay que tenerla en cuenta porque, o bien impedía su incorporación a un trabajo extradoméstico remunerado, o bien ahorraba el coste de externalizarla contratando a alguien normalmente otras mujeres-, fuera del grupo doméstico para que la realizara por ellas.

TABLA 4

Mujeres con hijos o parientes en edad no laboral en Úbeda y Laujar de Andarax (1751-52)

\begin{tabular}{|c|r|r|r|r|r|c|}
\hline & \multicolumn{3}{|c|}{ Úbeda } & \multicolumn{3}{c|}{ Laviar de Andarax } \\
\hline $\mathrm{N}^{\circ}$ Hijos/parientes & Casadas & Viudas & Solteras & Casadas & Viudas & Solteras \\
\hline 1 & 384 & 102 & 11 & 45 & 7 & 1 \\
\hline 2 & 246 & 62 & 3 & 41 & 6 & - \\
\hline 3 & 190 & 40 & 2 & 18 & - & - \\
\hline 4 & 89 & 22 & - & 2 & - & - \\
\hline 5 & 54 & 11 & - & - & - & - \\
\hline 6 & 24 & 2 & - & - & - & - \\
\hline 7 & 7 & 4 & - & - & - & - \\
\hline 8 & 3 & 2 & - & - & - & - \\
\hline 9 & 1 & - & - & - & - & - \\
\hline Total & 998 & 245 & 16 & 106 & 13 & 1 \\
\hline
\end{tabular}

Fuentes: tabla 1.

La mayoría eran mujeres casadas, tanto en Úbeda como en Laujar, seguidas de las viudas. Unas y otras se ocupaban del cuidado de sus hijos pequeños y, a veces, de hermanos, sobrinos, nietos o cuñados de corta edad. Las pocas solteras que se registran se dedicaban sobre todo a cuidar de hermanos pequeños o sobrinos menores. En Úbeda, entre las casadas se contabilizan un total de 998 mujeres, 245 viudas y apenas 16 solteras; mientras que en Laujar esos grupos de mujeres se quedaban en 106 casadas, 13 viudas y una soltera. Destacaban en todos los casos, especialmente, las que tenían entre 1 y 3 hijos.

En Laujar, sólo conocemos el trabajo y la remuneración que recibe cada mujer; pero no se aportan muchos más detalles. Algunos ejemplos serían el de la esposa de 37 años del jornalero Pedro Sánchez Garranchal de 38: "Se le pone de producto pr [por] Lucía Pinto su muger como hilandera de lana Vte [veinte] y cinco rs en 
cada un año". A la esposa de 44 años y a la hija de 20 del maestro de hilar seda Marcos Fernández Campoy, de 50 años y propietario de tierras de cultivo, se le asignan "otros ochenta rs pr [por] María Theresa y Maria muger e hija del susodicho como hilanderas de lana”. A la mujer de 36 años y a la hija de 15 del jornalero y propietario de tierras de cultivo y colmenas Francisco Ortiz de 40 años, se les imputan "otros sesenta y quatro rs pr Isabel hernandez y a Maria muger y hija del susodicho como hilanderas de lana” (Laujar, sig. 43640).

El número de hombres de cualquier edad de los que se registra su ocupación es de 660 en Laujar y de 3.072 en Úbeda (tablas 2 y 3). Sobre dichos datos, vale decir lo mismo que lo indicado antes para las mujeres respecto a las cantidades más bajas de activos masculinos en comparación con todos los que aparecían con alguna ocupación.

Las principales ocupaciones de los hombres en Laujar se correspondían con el trabajo en la industria textil y en la agricultura, en función de su condición de labradores o trabajando de jornaleros del campo, y por ese orden. Esto refleja una distribución social y económica más compleja y menos polarizada que la que aparece en Úbeda. En este sentido, se debe tener en cuenta que el tamaño de la población de esta última era muy superior al de Laujar, lo cual influye directamente tanto en el grado de división del trabajo como en la mayor especialización de los núcleos grandes, como se observa en la tabla 3.

El trabajo masculino responde a la demanda de mano de obra agrícola, tanto temporal en las épocas de casi pleno empleo de la recogida de las cosechas, como estable a lo largo de todo el año en los servicios y la ganadería, ocupando los puestos de cabeza los jornaleros del campo y eclesiásticos. El número de jornaleros del campo en las fuentes estaba inflado, por lo que se ha tenido que hacer una corrección a la baja, que son los datos aportados. Esto era así porque se autocalificaban como jornaleros algunos hombres -a veces incluso grandes labradores- para pagar menos impuestos, cuando en realidad eran pequeños o medianos arrendatarios o propietarios de tierras - pegujaleros-, que completaban sus ingresos trabajando temporalmente por cuenta ajena ${ }^{12}$. Pero no cabe duda de que en la Úbeda del siglo XVIII, existía una clara separación entre los más pobres y los más ricos, sobre todo algunos canónigos y presbíteros. Estos eran verdaderos emprendedores y empresarios en el sentido actual del concepto. Realizaban negocios especialmente arrendando sus tierras libres o vinculadas a las capellanías que regentaban y, como veremos, llegando a tratos con los campesinos de cada localidad.

En el grupo de los más poderosos económicamente también se incluían los nobles ubetenses y algunos labradores y pastores. El siguiente conjunto más numeroso era el de pegujaleros, que aspiraban a conseguir más tierras en arrendamiento o propiedad y elevarse hasta la categoría de labradores. La distribución de profesiones refleja en el caso de Úbeda una mayor especialización y diversidad de actividades profesionales, comerciales, industriales y artesanales que en Laujar, fiel consecuencia del tipo de poblaciones a las que se refieren los datos. Úbeda es un modelo de una ciudad de tamaño medio con funciones religiosas, administrativas y económicas, en la que la industria textil había entrado en crisis. Laujar representa un modelo de un pueblo de tamaño pequeño que había diversificado su economía, especializándose en la manufactura textil sin perder su base agraria, aunque en esos años ya se estaba notando también la crisis del sector textil.

\section{Contratos Y ACUERDos DE TRABAJO EN LA ACTIVIDAD TEXTIL, LA AGRICULTURA Y LOS SERVICIOS}

El trabajo de las mujeres y niños estaba peor pagado y, por tanto, su contratación era más barata. ${ }^{13}$ Esto podía favorecer la actividad femenina e infantil, independientemente de que estuviese registrada. ${ }^{14}$ Existen estudios que demuestran una abundante actividad laboral femenina remunerada durante todo el año (Humphries y Sarasúa, 2012, p. 46. Para Holanda, van Nederveen y Schmidt, 2008; Schmidt y van Nederveen, 2012. Para Inglaterra, Burnette, 2004, 2008; Humphries, 2010; Atkinson, 2012; Humphries y Weisdorf, 2014). Pero hay que tener en cuenta que a mediados del siglo XVIII lo importante no era el salario 
individual, sino los recursos familiares en especie o en dinero como rentas o salarios, con los que se cubrían las necesidades tanto de las familias extensas o complejas como de las nucleares. En los casos de nuestro estudio aún persistía la importancia de las familias extensas, al representar entre la población seglar de Laujar un $33 \%$ y en Úbeda un $31 \%$.

Por tanto, cuando todavía no se había generalizado el modelo de ganador de pan ("male breadwinner") y sostén de la familia, los recursos o ingresos monetarios que podían obtener mujeres y niños, aunque fuesen pequeños, eran importantes para mantener a la familia (Horrell y Humphries, 1995, 1997; Borderías, 2013, 2014; Borderías, Pérez\#Fuentes y Sarasúa, 2014, pp. 14, 32; Borderías y Gálvez, 2014). Además, las jóvenes que trabajaban de criadas, de acuerdo con lo pactado, eran remuneradas en especie, representando no sólo una boca menos a alimentar en su familia, sino que también le podía aportar alimentos, telas, cera, leña, vestidos o zapatos usados, que les entregaban como pago en las casas donde servían. ${ }^{15}$

Una diferencia entre los tratos salariales a que se llagaba en Úbeda y Laujar, es que en la primera se aportan en las fuentes los salarios diarios y a veces las rentas anuales, mientras que en la segunda se declaran las rentas anuales y apenas se anotaban datos de salarios o jornales diarios. No obstante, es preferible contar con las rentas anuales procedentes de todo tipo de recursos, y no sólo de los ingresos salariales diarios, porque por el hecho de que sepamos el jornal diario no nos garantiza conocer los ingresos o rentas anuales, al estar condicionados por el número de días de trabajo a lo largo del año, como se explicará más adelante.

Como se ve en la figura 1, el trabajo en la industria textil sí estaba remunerado monetariamente.

FIGURA 1.

Escala de rentas anuales de las mujeres en las ocupaciones textiles sin pluriactividad en Laujar y con pluraictividad en Ubeda (1751-52)

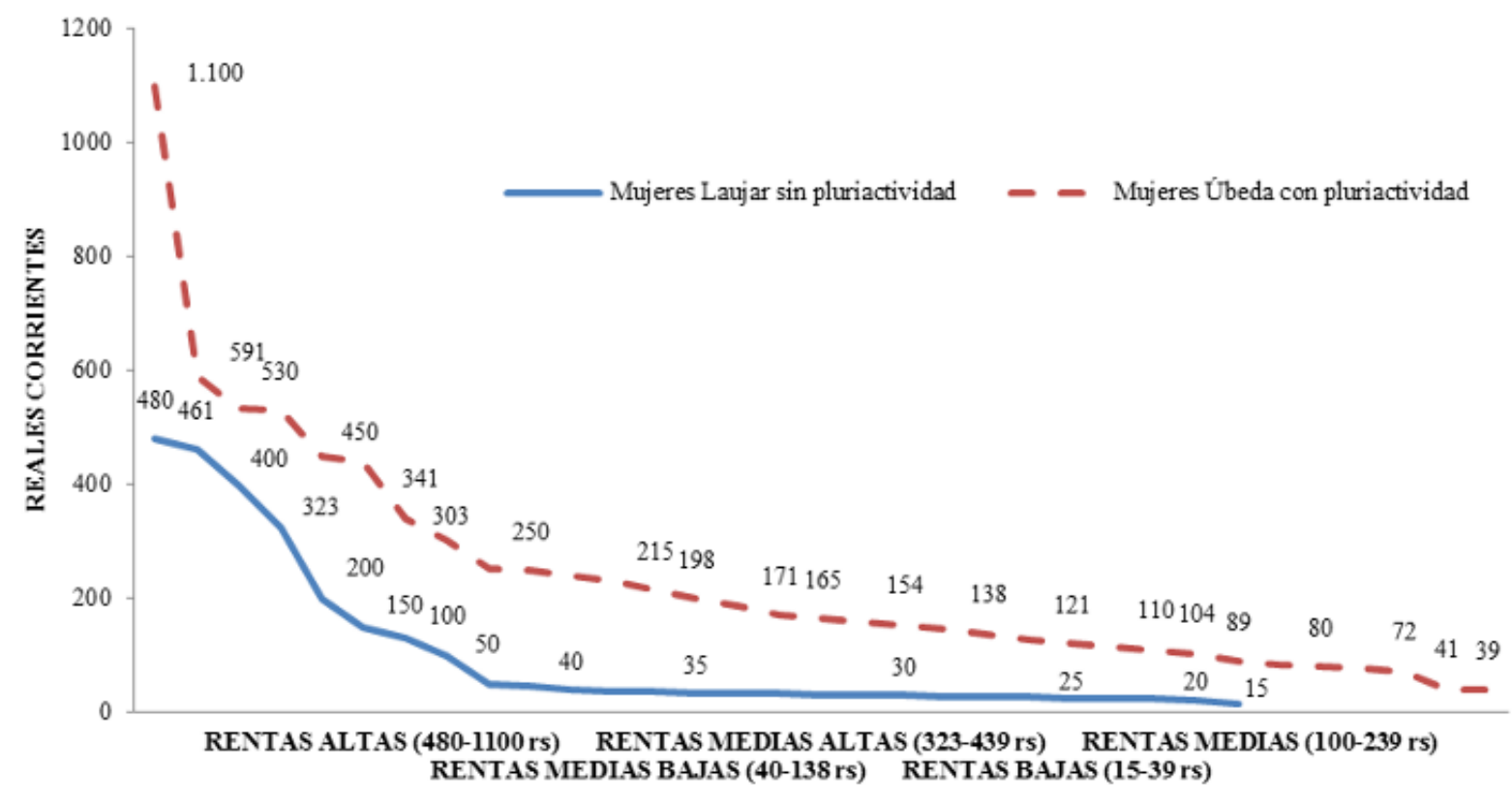

Fuentes: tabla 1.

En el caso de Laujar de Andarax, se conocen las rentas salariales anuales de hilanderas, cardadores, tejedores, etc., que no incluían comida, vestido ni vivienda. Por el contrario, en Úbeda no constan en las fuentes las remuneraciones de las mujeres trabajadoras del sector textil. Por este motivo se ha adoptado un cálculo indirecto, basado en la proporción que representaba en Laujar la renta anual de una hilandera respecto a su equivalente masculino, que venía a ser 5 veces inferior para las mujeres. Pero las diferencias de rentas 
salariales anuales que se hacían constar en los memoriales del Catastro de Ensenada en Laujar, demuestra que en el caso de las hilanderas y tejedoras existía una negociación individual hasta alcanzar un acuerdo en el trato correspondiente con el empleador. Por el contrario, los tratos a los que se llegaba en el caso de los hombres dan como resultado una mayor homogeneidad salarial para cardadores, canilleros, hilanderos de seda, tejedores y tundidores, dentro de unas determinadas franjas y por categorías y especialidades textiles. La explicación puede estar relacionada con la tradición y cultura gremial de la que procedían dichas actividades textiles. Ahora bien, a los gremios como tales no se alude en los memoriales individuales que se presentaron. De hecho, existe confusión cuando se autoclasifican unas veces como oficiales y otras como maestros, ya que el sistema gremial había entrado en decadencia incluso en los grandes núcleos urbanos, como Sevilla, y aún más en ciudades de tamaño medio como Antequera, Écija, Béjar (González Enciso, 1998, pp. 133-136; Parejo, 1987, pp. 231-232); Valiente, 2014, p. 152-159, 265-270; Ros, 1998, pp. 26-29. Para el cambio tecnológico que precipitó la crisis del textil tradicional manual, Benaul, 1995, p. 200), Úbeda o en pueblos pequeños como Laujar. Más seguro es que las rentas monetarias anuales cobradas realmente por mujeres y hombres dependiesen de variables como el género, la edad y el número anual de días de trabajo efectivo y, por supuesto, de la pluriactividad, que afectaba tanto a mujeres como a hombres. ${ }^{16}$

Según señalaron Tilly y Scott (1989), en Francia e Inglaterra las mujeres de clase baja siempre trabajaron por un salario u otro tipo de remuneración en especie. Numerosas madres e hijas de familias trabajadoras estuvieron vinculadas a actividades económicas de diversa índole y sus escasos ingresos fueron decisivos a la hora de marcar la diferencia entre ser pobre y pasar hambre la familia. En realidad, el trabajo de las mujeres casadas francesas e inglesas formaba parte de los valores tradicionales y de la cultura de las clases populares y se esperaba que una buena esposa llevase algunos recursos a la familia. Las recurrentes crisis y las escaseces consiguientes entre los sectores de población con rentas bajas, obligaron frecuentemente a las mujeres casadas a ganar algo de dinero en el mercado laboral. Por otra parte, aunque el salario del marido fuera el principal, pocas familias dependían exclusivamente de este ingreso solía ser insuficiente para asegurar la reproducción familiar. Por tanto, el hecho de que el empleo femenino fuera ocasional no disminuía la importancia que tenía para la economía familiar (Tilly y Scott, 1989. Véase también en Mayordomo, 2000).

En los tratos a que se llegaba se buscaba completar las fases de menor actividad, con ocupaciones y labores que les permitiesen obtener algunos recursos en especie o rentas monetarias a lo largo de todo el año. De hecho, lo que se desprende de los memoriales del Catastro de Ensenada de Laujar y de Úbeda es que, con la excepción de los que especifican que son trabajadores temporeros, como los jornaleros del campo o los jornaleros de las fábricas textiles, no había períodos inactivos. Todos o casi todos, mujeres, hombres y niños, estaban ocupado en algún menester, fuese remunerado o no. A título de ejemplo, en Laujar una hilandera de lana trabajaba a temporadas como criada y era pequeña propietaria de tierras de cultivo, otra contaba con más recursos gracias a la cría y engorde de dos cerdos y una tercera hilandera tenía en propiedad dos casas que arrendaba a terceros y era propietaria de tierras de cultivo.

Respecto a los hombres de Laujar, un maestro hilandero de seda era dueño de una panadería, propietario de tierras de cultivo y de colmenas. Un maestro de la fábrica de paños trabajaba también en el cultivo de los árboles de moreras de su propiedad. Un maestro de sastre tenía una tienda de mercería. Un maestro hilandero realizaba servicio de arriería con un asno en las fases de inactividad en la hilatura. Un jornalero del campo se dedicaba a cultivar su pequeña propiedad de tierra en las temporadas en que no había otros trabajos agrícolas. Un maestro de hilar seda completaba sus ingresos con el cultivo de su propiedad de tierras de cultivo. Otro jornalero del campo complementaba su trabajo temporal con la explotación de tierras de cultivo de su propiedad y de colmenas. Un tabernero era cardador de lana por temporadas y tenía abierta una tienda de aceite. Un fabricante de paños era propietario de tierras de cultivo, de ganado y colono de tierras de eclesiástico. Otro fabricante de paños era también maestro de la fábrica de paños y explotaba unas colmenas. Un maestro hilandero de seda trabajaba también como maestro tejedor de paños, y a tiempo parcial en su 
pequeña propiedad agraria. Lo mismo hacía un tejedor de paños que era propietario de tierras de cultivo. Y así podríamos seguir multiplicando los casos.

En Úbeda también se detecta la pluriactividad. Las hilanderas trabajaban las distintas materias primas textiles como lana, lino, cáñamo, estopa, o empleaban su tiempo como costureras o haciendo media o lejías. Algunas podían tener la propiedad de pequeñas parcelas de tierra de cultivo, de casas o de partes de las mismas, por derechos de herencia propios o de sus hijos. La hilandera Ana Alaminos Navarrete, que era viuda sin hijos y clasificada como pobre de solemnidad, en realidad, vivía agregada, aunque ella estaba en casa independiente, a la familia de su vecino de puerta con puerta Francisco Ordóñez de 63 años y casado seguramente con una mujer también mayor. Debía tener un trato con ese matrimonio como sirvienta externa para hacer las tareas de la casa. A su vecino le clasificaban sin ejercicio por ancianidad o enfermedad, a pesar de que declaraba el ejercicio de "garbancero", "que por mi industria por algunos garbanzos por menudo me rinde al año 550 rs con que me mantengo". Pero estas circunstancias obligaban a la hilandera a completar sus escasos ingresos -que podían suponerle una renta anual de $39 \mathrm{rs}$, al tener trabajo de hilandera apenas unos 50 días-, con un trabajo especializado y mejor pagado, que era "hacer legías", por cuya venta obtenía 200 rs anuales, es decir, en total podía llegar a ganar unos 239 rs al año:

"Primeramente declaro ser de edad de cinquenta y ocho años, viuda de Alonso Ruiz, sin familia alguna, que me mantengo de ylar, y hazer legías, y por no tener bienes algunos trato ni comercio, doi la presente en virtud de lo mandado, y por no saber escrivir Rogué a un testigo lo firmase por mí, que lo fue Juan Moreno, en la dha ciud a quatro días del mes de Marzo de mil setecientos cinquenta y dos años" (Úbeda, sig. 7947).

Otro caso sería el de María Arjona Cobo, hija de un jornalero que vive con sus padres y sus hermanos menores. Trabajaba como costurera y lavandera, y a la misma se refiere el hijodalgo y Visitador de la Casa y hospital de los honrados viejos del Salvador, D. Bartolomé Andrés de Ventaja: "Se les laba y remienda la ropa a los menzionados Padres y la de refectorio y sacristia a cuyo fin ay una muxer asalariada que gana cada año veinte y qtro [24] Ducados [264 rs]" (Úbeda, sig. 7947). Un último ejemplo podría ser el de un jornalero del campo viudo que vive con su hija soltera mayor de 18 años: "Declaro me hallo en edad de quart ${ }^{\mathrm{a}}$ y tres [43] años, viudo, y de familia tengo una hija qe [que] se ocupa en hilar lana, lino, y cáñamo” (Úbeda, sig. 7947). En el mismo se refleja perfectamente la diversificación de la actividad textil, adaptándose a la demanda de los distintos productos para poder así alcanzar unos 275 días de trabajo al año, aunque a pesar de ello apenas se llegaba a una renta de 39 rs anuales. Pero servía para completar los ingresos del padre por su trabajo de jornalero del campo temporero que, de acuerdo con los tratos verbales habituales, podía llegar a ganar 3 rs diarios.

En el sector agrario, una mujer llevaba la administración de la explotación de una pequeña parcela cultivada de trigo o cebada con la rotación de año y vez, viñedo y olivar, era además propietaria de una casa que tenía arrendada y de la $6^{a}$ parte de otra que también tenía alquilada. Otra mujer era administradora como madre, tutora y "curadora" (cuidadora) de sus hijos de un primer matrimonio, de la propiedad de una parcela de tierra de poco más de una hectárea con 3.200 vides y propietaria de la mitad de una casa arrendada en 88 rs, aunque sólo percibía su mitad de 44 rs.

En realidad, como se ha advertido antes, algo fundamental era el número de días al año que se conseguía ser contratado, y eso obligaba a practicar la pluriactividad. Como se aprecia en la tabla 5 para los hombres, tanto en Laujar como en Úbeda era una manera de obtener mayores rentas anuales, aunque no siempre se lograba, como lo demuestran los casos en que pese a la pluriactividad había hombres en Úbeda cuyas rentas anuales eran de apenas 110 rs anuales; por tanto, inferiores a las de los casos en que con una sola actividad se alcanzaba el umbral de los 200 rs como renta más baja. 
TABLA 5

Umbrales de rentas anuales masculinos sin pluriactividad y con pluriactividad Laujar de Andarax (1751) y Úbeda (1752)

\begin{tabular}{|l|c|c|c|c|}
\hline & \multicolumn{2}{|c|}{ Laujar } & \multicolumn{2}{c|}{ Úrbeda } \\
\hline & $\sin$ plugiactividad & con plugiactividad & sin plupiactividad & con pluciactividad \\
\hline Rentas Altas & 3.895 & 6.396 & 1.642 & 2.013 \\
\hline Rentas Medias Altas & 1.500 & 1.664 & 1.375 & 1.558 \\
\hline Rentas Medias & 750 & 1.032 & 1.100 & 1.277 \\
\hline Rentas Medias Bajas & 400 & 578 & 728 & 847 \\
\hline Rentas Bajas & 80 & 150 & 200 & 110 \\
\hline
\end{tabular}

Fuentes: tabla 1.

En todos los casos las rentas obtenidas con pluriactividad eran superiores a las conseguidas sin ella, con la excepción de las rentas bajas en Úbeda. Esto se debe a que los 200 rs que se perciben como la menor de las rentas bajas son las retribuciones de tejedores (oficiales o maestros), que no registran ninguna otra actividad ni fuentes de ingresos. En cambio, los 110 rs de las rentas más bajas corresponden a un aprendiz de cordonero de 21 años, que era propietario de tierras de cultivo y arrendador de una casa, y que por tanto estaría ocupado también en el trabajo agrícola y en la administración de la casa que tenía arrendada (Úbeda, sigs. 7946, 7947). En definitiva, pese a darse un tipo de trabajo irregular y una fuerte pluriactividad, lo cual concuerda perfectamente con lo que se conoce del trabajo durante el siglo XVIII, existía una relación directamente proporcional entre la pluriactividad y el aumento de las rentas anuales masculinas, con la única excepción antedicha.

Por tanto, en los arreglos a que se llegase el número de días de trabajo era una cuestión importante. Igual que si se acordaba el pago en especie o como un complemento. En Úbeda, las fuentes registran las cantidades monetarias que se entregaban, y si se completaban con el suministro de trigo, harina, aceite, pan, vino, carbón, etc. En los tratos de criadas internas en las casas apenas se acordaba un salario monetario, pagándose con la comida, el vestido, la habitación y la enseñanza de hacer bien las labores domésticas, desde limpiar, lavar o hilar y coser hasta cocinar. El destino de muchas mujeres empleadas de sirvientas desde niñas, era casarse y pasar a hacer esas mismas tareas en su propio hogar. Pero sobre todo hay que tener en cuenta que el ahorro de tener cubiertas las necesidades básicas a cargo de los empleadores -que por supuesto se pueden valorar en términos monetarios-, compensaba la inexistencia de un salario, como por ejemplo decían dos sobrinos menores de 18 años de Juan Carrizo de Úbeda, para el que trabajaban como "ganaderos de cerda por la comida" (Úbeda, sig. 7948); o el caso de una sirvienta de Isabel Ruiz, que firmaba su memorial y declaraba su: "estado zelibato, y que estoi sirviendo a Dna Maria de la Torre por la comida solamte [solamente]” (Úbeda, sig. 7949).

Los jornaleros del campo procuraban completar sus rentas trabajando una pequeña propiedad de tierra o llegando a acuerdos de arrendamiento o aparcería. En las tareas agrícolas de temporada, difícilmente superarían los 180 días, pudiendo ganar un máximo de 540 rs al año, cuando no menos. Así lo confirman los salarios inferiores declarados por otros trabajadores del campo, como muleros, gañanes o pastores.

\section{LOS TRATOS A ESTILO MAJOLEROS Y PLANTÍO EN ÚBEDA}

Unos tipos de tratos frecuentes que firmaban tanto mujeres como hombres en Úbeda eran los llamados a estilo majoleros o majuelos y a estilo plantío. Consistían en entregar una parcela de tierra inculta para una primera puesta o plantación de olivas o viñedo, que en el caso del acuerdo a estilo majoleros se repartía al cabo de 9, 10 o 12 años. En el estilo plantío "se partía” a los 8 años. De acuerdo con estos contratos, la partición se 
hacía a partes iguales entre el propietario de la tierra y su cultivador. Este último no tenía obligación de pagar ningún tipo de arrendamiento durante el tiempo de puesta en cultivo hasta que diese fruto. La ventaja para ambas partes era que el propietario ponía en cultivo una tierra que antes no producía nada y no obtenía por ella ninguna renta. Para el cultivador el trato de majoleros o plantío tenía varias ventajas. En primer lugar, se autoempleaba y tenía trabajo en los tiempos muertos o de hacer pocas labores en el campo. En segundo lugar, a cambio de su trabajo, o bien disponía de más superficie cultivada -ampliar la linde es una obsesión en muchos campesinos-, o bien accedían a ser propietarios de tierras por primera vez. De esa forma una parte de la propiedad eclesiástica estaba pasando a manos privadas en el siglo XVIII. Este sistema permitió tanto a mujeres como hombres, ya fuesen hortelanas/os, arrendatarias/os, pequeñas/os propietarias/os, ya fuesen jornaleros del campo sin tierras e incluso algún artesano, como el caso de un alfarero, convertirse en propietarios agrícolas.

Las dificultades para conseguir un trato a estilo majoleros o plantío, venían dadas por la desconfianza del propietario o usufructuario de la tierra con el que se debía llagar al acuerdo. De otro lado se tenía que contar con una capacidad de autofinanciación suficiente para trabajar los años necesarios -entre 8 y 12 años-, sin obtener una renta de esa explotación. Por ese motivo lo hacían los jornaleros del campo que contaban con un salario fijo, o quienes ya poseían tierras en arrendamiento o propiedad de las que obtenían una renta para su supervivencia y tenían suficiente potencial de factor trabajo. Un ejemplo es el de la hortelana y pegujalera Catalina María Rodríguez, que tenía 2 celemines de tierra con un plantío de estacas de olivar propiedad de un eclesiástico, "que se a de partir cumplidos los nueve $\mathrm{a}^{\circ}$ [ [años] a estilo de Majoleros para los que ban corridos quatro". Se trataba de una viuda cuya familia se componía de 4 hijos, un nieto y 3 hijas mayores de 18 años, una nieta de 17 y otro nieto de 14 años. Los 6 hombres trabajaban como hortelanos en sus tierras, mientras que de las 4 mujeres no consta su actividad, que debía ser las tareas domésticas.

Otro caso sería el del jornalero Juan Salas, casado con dos hijos menores de 10 años, quien declara:

“Estoi Plantando una viña una pieza de tierra propia de la capellanía que posee Dn. Juan Lopez Presvto [presbítero] de esta ciud [ciudad], a estilo de Maxoleros, en el sitio de los caldereros dista media legua, que para los diez, van corrídos seis años, consíste en tres qued.s [cuerdas] con el plantío de tres mil vídes y catorze estacas [olivas], que al partír me toca la mítad, con

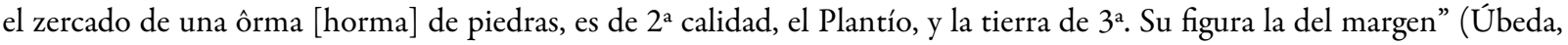
sig. 7947).

Una muestra de trato a estilo de plantío, sería el que tenía acordado la “pobre de solemnidad” Juana Jiménez con el pegujalero Blas Piqueras ${ }^{17}$. Ella era viuda sin hijos propietaria del equivalente a 1,4 hectáreas de tierra donde tenía plantadas viñas, olivas y se cultivaba escaña, centeno o lentejas con la alternancia de año y vez. También contaba con la renta de un censo a favor de 16,5 rs anuales "puesto sobre el vínculo que posee María de Abad que de pte [presente] lo paga”. Pero como sus ingresos no eran suficientes, estaba obligaba a vivir a costa de su cuñado Dn Alonso de Aguirre, aunque lo califica de hermano, residente fuera de la ciudad de Úbeda en el pueblo cercano de Bédmar. Y Juana decía en su memorial:

“Tengo dada a plantar de viña una pieza de tierra a Blas Piqueras a estílo de Plantío que para los ocho as [años] van corrídos tres, y al partir me toca la mitad: en Valdecanales dista media legua, consiste en un[a] qda [cuerda] y seís Zs [celemines] con el Plantío de míll y qtas [quinientas] vídes" (Úbeda, sig. 7947).

Pero resulta que también tenemos, por contraste, el caso de una mujer de la nobleza que firma personalmente su memorial, en el que declara dos tratos a estilo de plantío. Se trata de $\mathrm{D}^{a}$ Inés Petronila Gutiérrez de Contreras Rivera, soltera con 25 años, apoderada y administradora de los bienes y rentas de D. Alonso Gutiérrez de Contreras Rivera, hijodalgo notorio soltero de 29 años, su hermano residente en la ciudad de Granada y abogado de la Real Cancillería. El primer contrato se había firmado con un presbítero que vivía con sus dos hermanos, sobre: 
"otra pieza de tierra en el sitio de la Huerta del Sillero, distante desta Ziud [Ciudad] un qto [cuarto] de legua que se conpone de Seis cuerdas y esta dada a plantío de viña y olivar a Dn. Agustín Anguita Ramírez pr [por] ocho as [años] de los qe [que] van corridos quatro y en estando para partir segun stilo [estilo] tocan dos cuerdas y media a cada uno" (Úbeda, sig.7950).

Un segundo trato a estilo de plantío para partir a partes iguales al terminar el plazo correspondiente, se había realizado con un jornalero casado que tenía tres hijos menores de 18 años, dos varones y una hembra. Se trataba de:

"una pieza de tierra de secano en el Sítío de la era de $\mathrm{St}^{\mathrm{o}}$ Thomas, distante de esta Ziud [Ciudad] un quarto de legua y esta dada a plantío de viña a Manuel Sánchez por ocho as [años] de los que van vencidos tres y se compone de dos cuerdas" (Úbeda, sig.7950).

También se desprende de toda esta información sobre acuerdos contractuales, que serían en su mayoría verbales, la existencia de una densa red de ayuda intervecinal e interfamiliar. Cuando se cruzan los datos de las personas que tenían en arrendamiento o alquiler sus tierras y casas, nos encontramos con que resultaban ser parientes o vecinos de las mismas calles. Las personas que aparentemente vivían solas, en realidad, estaban trabajando con sus vecinos más inmediatos. Así sucedía con las viudas o las hijas que trabajaban de criadas de sus vecinos, o estaban en lo que llamaban “en compañía”, "en asistencia”, etc. A los hombres les sucedía lo mismo, fuesen solteros, casados o viudos, trabajando como jornaleros, muleros, pastores, etc., con personas de su entorno en la misma calle. De donde se deduce que la confianza mutua, los lazos familiares o de amistad, la cercanía de la vecindad que permitía conocer a cada uno, el buen saber hacer o la buena fama, eran factores determinantes a la hora de llegar a un trato no sólo en la industria textil, sino también en las restantes ocupaciones.

\section{CONTRATOS DE TIPO “EN COMPAÑÍA" Y "ASISTENCIA"}

Eran acuerdos a que llegaban las mujeres de Úbeda a cambio de una remuneración en especie, y que normalmente suponían residir en el mismo domicilio en el que se servía. Como ejemplos de asistencia y compañía, tenemos la declaración de una hermana de un fraile del convento de la Santísima Trinidad, María Ávila de 48 años:

"que tengo a mi cargo, i expensas, una moza de dieziseis años que la e criado desde niña, por aberla sacado de la cuna de esta dicha ciudad, para que me sirva de compaña. Y que para nuestro alimento i vestido, no tengo otra inteligencia, ni industria, que la de serbir, y asistir a un hermano mio, Religioso" (Úbeda, sig. 7948).

Otro ejemplo es el de Da Lutgarda Baena Santerbas soltera:

"Prímeramente Declaro estar en edad de quarentta años, en estado de Doncella, en compañía, y asistensia y cassas en dicha Parroq $^{a}$ [parroquia] y calle de $\mathrm{D}^{\mathrm{a}}$ María de Baena y Santerbas mujer de D. Ant ${ }^{\circ}$ [Antonio] Muñoz, mi hermana y servida de su misma fam ${ }^{a}$ [familia] y criados que constan de su memal [memorial]" (Úbeda, sig. 7950).

El oficial de zapatero y coletero Francisco Copado de 40 años, incluye en su memorial a cinco hermanas que están en su compañía, la mayor María de 32 años y las otras menores de 25 años "que se ocupan en ylar y coser"; aunque su relación la podemos completar con la de su hermana mayor, una propietaria de tierras de trigo y cebada:

"Relación que io María Copado viuda de Andrés Gomez Corcino Vezina de esta Ciudad a la Calle la Corredera Parrochia de Señor San Nicolas doi en virtud del edicto fixado por el señor Dn Manuel de los Cuetos Juez Subdelegado para las Dilixenzias del establecimiento de la unica Contribuzión en la forma Siguiente= Primeramente Declaro estar en edad de treinta y dos años viuda y que mi familia se compone de quattro hermanas Doncellas maiores de veinte y zinco años y Que me exercito yo y mis hermanas en Coser y hazer otras haciendas de Muxeres" (Úbeda, sigs. 7946, 7947). 
Entre los ejemplos de estar en asistencia podemos citar los de las hermanas María y Josefa Rayo solteras de 40 y 35 años, que presentaron sus propios memoriales individualmente por ser propietarias ambas de parte de una casa, y la segunda de un olivar, pero agregadas a la familia de su hermano Alonso José de 28 años y maestro de sastre, el cual dice en su relación: "que se ocupan en trabaxar en la casa y en mi asistencia" (Úbeda, sigs. 7946, 7947). Otro caso sería el de una viuda de 51 años, Luisa Prieto, y su hija soltera Cándida Prieto mayor de 18 años, que en su memorial declaran: "nuestro exerzizio es el de costureras y a temporadas traigo una panadería tan corta que solo da para mantenernos". Pero lo interesante es que en el memorial de su yerno José Clemente Escos de 38 años -que era músico violinista, administrador de la fábrica de S. Juan Bautista, colector de la misma parroquia, administrador novicial de tierras de capellanía colativa y tenía comercio de vino- en nota de fecha posterior y con un aviso al margen donde se señala "ojo" son incluidas con nombres y apellidos, añadiendo "quíenes estan en mi asistencia", ya que inicialmente se había limitado a decir que estaba "casado y que mi familia se compone de una suegra y cuñada" (Úbeda, sigs. 7946, 7947). La viuda de 40 años, María Merino, propietaria de una casa que "gana por año toda ella con el dicho corral seis Dus [ducados] Vn [vellón]", es decir, obtiene una renta anual de 66 reales (rs), declara en su memorial que "no tengo hixos, solo tengo en mi asistencia una muxer menor de doze as [años]" (Úbeda, sig. 7950). Otros casos de estar en compañía serían el de una hermana de una propietaria de tierras con 1.500 vides y una casa que "mereze ganar de arrendamiento cinco ducados [55 rs] cada un año":

"Ana de Roxas vecina de esta ciudad de Ubeda, mi oficio texer lienzos ilar, coser, y labar, calle del campanario parroqia de San Nícolas. Declaro ser de cuarenta y quatro as. [años] de estado soltera, mi familia se compone de dos Hermanas, y dos sobrinos, la una Hermana de Hedad de treinta as. llamada María de Roxas estado soltera la que esta en mi compañía, otra de veinte y ocho as. viuda, llamada Juliana de Roxas, que esta sirbiendo en casa del Señor Marqs [Marqués] del Cadimo y tiene un hijo de tres as. llamado Manuel de Salamanca que también esta conmigo, la sobrína de Hedad de veinte y dos as. llamada Juana Urtado Ortiz que esta sirbiendo en casa de Dn Alexo Garzía Secretario del Cabildo de esta Ciudad” (Úbeda, sig. 7947).

La propietaria de tierras y casas Nicolasa Jesús Fernández de 52 años declara: "tengo en mi compañía a una ha [hermana] mía Viuda pa [para] q [que] me asista pues me hallo lo más de el año gravada con enfermed [enfermedad] q [que] padezqo havitual". Y su hermanastra por parte de madre Quiteria Ruiz Fernández dice:

"Primeramente declaro tener quarenta y seis a. de edad, en estado de Viuda, no tener hijo alguno, y estar viviendo en compañía de mi herma [hermana] Nicolasa de Jessus Fernandez en sus casas propias" (Úbeda, sig. 7947). Es decir, se trataba en su mayoría de parientes o familiares que realizaban la función de sirvientes, pero que por razones de prestigio no se les clasificaba como tales en la época. Algo a tener en cuenta a la hora de interpretar la información de las fuentes.

\section{RENTAS ANUALES DE MUJERES Y HOMBRES}

Las principales fuentes de rentas femeninas y masculinas se han recogido en la tabla 6 para el caso de Laujar de Andarax y en la tabla 7 para Úbeda, antes de pasar a continuación a analizar por separado cada una de ellas. 
TABLA 6

Fuentes de rentas femeninas y masculinas Laujar de Andarax (1751)

\begin{tabular}{|l|l|}
\hline \multicolumn{1}{|c|}{ Procedencia de las rentas femeninas } & \multicolumn{1}{|c|}{ Procedencia de las rentas masculinas } \\
\hline Arrendamiento cargos administrativos & Cargos administrativos \\
\hline Oficios textiles & Comercig \\
\hline Panaderia & Construcción \\
\hline Propiedad de fábricas textiles & Ganaderia \\
\hline Propiedad de molino de harina & Molineria \\
\hline Propiedad de tierras & Oficios artesanales \\
\hline Servicios como criadas & Oficios textiles \\
\hline & Propiedad de colmenas \\
\hline & Propiedad de fábricas textiles \\
\hline & Propiedad de tierras \\
\hline & Servicios como criados \\
\hline & Servicios eclesiásticos \\
\hline & Servicios sanitarios \\
\hline & Trabajo en el campo a jornal \\
\hline
\end{tabular}

Fuentes: tabla 1. 
TABLA 7

Fuentes de rentas femeninas y masculinas Úbeda (1752)

\begin{tabular}{|c|c|}
\hline $\begin{array}{l}\text { Procedencia de las rentas femeninas } \\
\text { Administración barberias }\end{array}$ & $\begin{array}{l}\text { Procedencia de las rentas mas culinas } \\
\text { Administración púlblica }\end{array}$ \\
\hline Administración del oficio de alguacil mayor & Administración tierras \\
\hline $\begin{array}{l}\text { Administración estanco de tabaco } \\
\text { Administración patronato eclesiástico }\end{array}$ & $\begin{array}{l}\text { Arrendamiento tierras } y / o \text { casas } \\
\text { Cargos a dministrativos } y / o \text { militares }\end{array}$ \\
\hline Administración platerias & $\mathrm{Caza}$ \\
\hline $\begin{array}{l}\text { Administración tierras y/ocasas } \\
\text { Arrendamiento cargos administrativos }\end{array}$ & $\begin{array}{l}\text { Comercio } \\
\text { Construcción }\end{array}$ \\
\hline Comercio & Cultivo de huertas \\
\hline $\begin{array}{l}\text { Costura } \\
\text { Chocolateria }\end{array}$ & $\begin{array}{l}\text { Esquilax } \\
\text { Fabricación de aceite }\end{array}$ \\
\hline Fabricación aceite & Fabricación de ja bón \\
\hline Fabricación legias & Ganaderia y pastoreo \\
\hline Lavanderia & Ganchero de madera \\
\hline $\begin{array}{l}\text { Limosnas } \\
\text { Oficios textiles } \\
\text { Panaderias }\end{array}$ & $\begin{array}{l}\text { Hacer mandados } \\
\text { Mayordomia/actministración particular } \\
\text { Molineria de harina y panaderia }\end{array}$ \\
\hline $\begin{array}{l}\text { Propiedad de tierras } \\
\text { Servicios como cocineras } \\
\text { Servicios como criaclas }\end{array}$ & $\begin{array}{l}\text { Mulero } \\
\text { Oficios artesanales } \\
\text { Oficios textiles }\end{array}$ \\
\hline Servicios de asistencia y compañia & Plateria \\
\hline \multirow[t]{8}{*}{ Servicios sanitarios } & Propie dad de colmenas \\
\hline & Propieclad de tierras \\
\hline & $\begin{array}{l}\text { Serticios como músic os } \\
\text { Servicios de barberia }\end{array}$ \\
\hline & Servicios de cochero \\
\hline & $\begin{array}{l}\text { Servicios de vigiancia de olivares } \\
\text { Servicios eclesiásticos }\end{array}$ \\
\hline & Servicios per sonales, de spenseros y como criados \\
\hline & $\begin{array}{l}\text { Servicios sanitarios } \\
\text { Suministro de leña }\end{array}$ \\
\hline & Trabajo en el campo a jornal \\
\hline
\end{tabular}

Fuentes: tabla 1.

\section{RENTAS FEMENINAS}

Las rentas y días de trabajo se negociaban de forma individual. Es necesario tener esto en cuenta a la hora de interpretar las rentas monetarias, que se registran en las fuentes expresadas en reales corrientes y como cifras absolutas y no promedios ${ }^{18}$. Las cantidades declaradas se correspondían con las realmente percibidas 
de acuerdo con los tratos pactados. Una información que tiene bastante fiabilidad. La razón reside en que en las revisiones -que denominaban confrontación o confrontada- que se realizaron de forma inmediata en la propia época, cuando una cantidad de superficie cultivada, o el arrendamiento de una casa no se correspondía con la cantidad declarada, se le asignaba normalmente al alza o, a veces, a la baja, la cantidad que realmente se pagaba ${ }^{19}$. Pese a todo no es descartable que hubiera cierta ocultación en los memoriales presentados. De hecho, tanto en Laujar como en Úbeda todos fueron revisados. Y con la excepción de las superficies cultivadas, las calidades de las tierras y las rentas imputadas a los arrendamientos urbanos, prácticamente, ninguno de los restantes conceptos declarados se rectificaron por los peritos incluyendo, por tanto, las rentas del trabajo.

Pero no cabe duda, que para conocer realmente las rentas anuales percibidas se deben saber los días trabajados. Y existe el problema de calcular el número de días trabajados anualmente, a partir de lo que se pactaba en los tratos individuales entre las partes. Según los memoriales donde aparecen declarados los días efectivos que se trabajaba, parece que los jornaleros del campo, tejedores, albañiles, canteros venían a hacerlo unos 100 días al año y respecto a los molineros de tres a tres meses y medio, sin que en ningún caso se haga referencia al número de días que trabajaban las mujeres. Por tanto, esto afectaba al trabajo agrícola, a la construcción y a la manufactura textil; pero no a los ganaderos u otros oficios manufactureros o artesanales, ni a las actividades de servicios en las que mujeres y hombres trabajaban todo el año con la excepción de las festividades correspondientes, ${ }^{20}$ como sería el caso de una estanquera de Úbeda, que firma de su puño y letra su memorial:

"Relación Que Yo Da Ana Castaño Veza [vecina] de esta Ciud [ciudad] y estanquera del pr [por] menor de la Renta del
Tavco [tabaco] en ella [...] Declaro ser de treinta as. [años] Viuda con tres hijos de menor edad el mr [mayor] de Doze as. y
una mujer q me sirve de edad de Quarenta y ocho as. Viuda q componemos de familia Zinco personas. Asimismo Declaro
tengo pr tal estanquera Quatro [4] Rs [reales] Vn [vellón] q. se me libra pr mi trabaxo.= esto se entiende por dia" (Úbeda,
sig. 7950).

Otro ejemplo es el de Inés Jiménez de 36 años, viuda con dos hijos menores que podemos calcular que trabajaba 275 días del año:

"y que para alimentarlos me Valgo de la yndustria de mi trabajo de hazer media y hilar lana. Poseo por mía propia, la quarta parte de una casa [...] y gana de arrendamiento ocho ducados [88 rs] a el año" (Úbeda, sig. 7947).

Por tanto, se ha optado por aportar las distintas rentas anuales registradas en las relaciones individuales, que a veces son coincidentes y otras no. Esto es lo que explica las distintas cantidades que aparecen. Cada una de ellas se corresponde con la información que consta explícitamente en algún memorial ${ }^{21}$. La principal conclusión que se desprende de esta información es que, tanto en Laujar como en Úbeda, se aprecia la existencia de la pluriactividad, al obtenerse ingresos de distintos trabajos a lo largo del año. Un caso frecuente era el de los jornaleros del campo con algún animal de carga como jumentas, asnos, de los cuales se dice en las RG, "sin perjuicio de su jornal porque aprovecha[n] los intermedios regulares, vende[n] algunos géneros de quincalla”. Era la situación de Pedro Bausán, un jornalero y buhonero de Úbeda con 25 años, al que le regulaban una utilidad de 1.100 rs al año (Úbeda, sig. 7946). Por otra parte, la pluriactividad también afectaba a los trabajadores del sector textil. Un cardador o peraire declaraba que aparte de su salario diario los días que trabajaba, obtenía un complemento de renta "por trato y comercio de bayetas", por el que le imputaban 550 rs al año (Úbeda, sig. 7946). Es evidente que se buscaba diversificar las fuentes de rentas y evitar los periodos desocupados sin ingresos.

No parece que existiese una verdadera especialización, y esto se detecta mejor en Laujar, pudiendo una mujer o un hombre realizar diversos trabajos en función de la baja cualificación que requerían. Las mujeres con rentas anuales más elevadas eran aquellas que administraban sus bienes, aunque había también algunas cardadoras y tejedoras con rentas anuales más elevadas que las de otras mujeres trabajadoras textiles; pero en cualquier caso muy por debajo de las obtenidas por los hombres. Las rentas más bajas de las mujeres eran las que pactaban en sus acuerdos las hilanderas y las criadas. 
Entre las mujeres la renta más elevada registrada en Laujar corresponde a los 5.332 rs que declara $\mathrm{D}^{\mathrm{a}}$ Antonia Chacón, de la que sólo sabemos que era soltera y mayor de edad, que administra sus bienes como propietaria de una casa cortijo con tierras de riego de "vega barchela" 22 de $1^{\text {a }} 2^{\text {a }}$ y $3^{\text {a }}$ calidades y de tierras calmas de secano, viñas, árboles propios en tierras ajenas, olivares y morales de $1^{\text {a }}$ calidad, ganado lanar y de labor. A ésta le sigue una cardadora con 480 rs de renta anual y una tejedora con 412 rs. Entre 200 y 400 rs se situarían una labradora, una panadera y una hilandera y por debajo de esas cifras una fabricante de paños, una molinera y las criadas. Las rentas mínimas registradas se corresponden a una mujer que administra la propiedad de su casa por la que percibe un alquiler de $8 \mathrm{rs}$, una criada que gana 12 rs, una hilandera de lana 15 rs y una molinera 46 rs.

Las rentas más elevadas de los hombres en Laujar eran las que correspondían a los fabricantes de paños y las más bajas a los jóvenes canilleros que trabajan con sus oficiales o maestros cardadores y tejedores, que eran sus propios padres o hermanos mayores.

En Úbeda, las mujeres con rentas anuales más elevadas eran administradoras de sus bienes o derechos de propiedad de sus hijos, algunas propietarias de tiendas de especería y mercería, pegujaleras (propietarias $\mathrm{o}$ arrendatarias de tierras), ${ }^{23}$ tintoreras, horneras o arrendatarias de hornos de pan, una enfermera del hospital de Santiago y las tejedoras que habían diversificado su actividad ante la inminente crisis local de las manufacturas textiles, y se dedicaban a la venta de pan y otras cosas. Pero siempre obtenían las rentas anuales más altas las mujeres que tenían una especialización, como las chocolateras, panaderas, estanqueras, esparteras, o las que contaban con distintas fuentes de ingresos, como podían ser los casos de costureras que además eran propietarias de tierras de cultivo y tenían arrendadas varias casas de su propiedad; o los casos de una costurera y panadera temporera; una hilandera de lana y panadera; otra que era hilandera, costurera, propietaria de tierras de cultivo y arrendadora de varias de sus casas.

De la mujer ubetense que tenía registrada una renta mayor sólo sabemos que era una viuda mayor de edad; la cual, según las RG, era dueña de una tienda "de espezería y mercería, propia de Cathalina Ruiz, en la parroquia de Santa María, que maneja Francisco Lubiers, su sobrino, y le utiliza dos mil y doszientos reales”, aunque resultaba ser ella la que le "mantiene [como] un factor de maior edad, casado, tres hijas de este y tres sobrinas suias” (Úbeda, sig. 7946). La siguiente era Rita Cobo, una viuda de 40 años con dos hijos varones de 8 y 11 años que "se ocupa en una tienda que tengo de Alfaarero que es cozer vedriado" (Úbeda, sig. 7947), y que declaraba una renta anual de 1.980 rs. Entre 1.500 y 1.650 reales de renta anual se situaban una panadera y una propietaria de una botica; entre 1.000 y 1.500 rs una labradora, una pegujalera, una tendera de puerta cerrada de especería y una propietaria de una tienda de alpargatero; entre 550 y 800 rs aparecen una hornera, una bodeguera y una chocolatera; entre 450 y 500 rs una propietaria de los derechos de la escribanía de millones, la estanquera de tabaco y una molinera de aceite; entre 350 y 400 rs una propietaria de una barbería, una de tienda abierta y una de tienda de espartería; entre 250 y 300 rs una arrendataria de una tenería y una propietaria del derecho de escribano de número que lo arrendaba; entre 100 y 200 rs, una trabajadora en majar esparto, una en el comercio con azúcar y vino, una administradora del alquiler de dos casas de cuyos ingresos sobrevivía, una de un patronato del que era patrona y una cocinera en el hospital de Santiago; por debajo de 100 rs anuales se situaban mujeres que trabajaban haciendo media, hilando lana o cosiendo, una tratante de género al por menor y las criadas.

Por tanto, las rentas más bajas se correspondían con el trabajo remunerado de criada y con lo que se percibía por el alquiler de casas. Es decir, las mujeres que disponían de una sola fuente de ingresos. Resultaba ser el caso de algunas administradoras que realmente sólo contabilizaban el cobro del arrendamiento de una casa o de una parte de ella. Las lavanderas tenían tratos anuales cerrados de 44 reales por su trabajo, que sería de una vez por semana con quienes las contrataban, pero no se hace constar en ningún caso los días de trabajo efectivo que realizaban. Las únicas excepciones eran la lavandera del Hospital de los honrados viejos de El Salvador y la del Hospital de Santiago, que recibían unos salarios muy superiores por 264 días de trabajo al año. 
Las tejedoras, hilanderas, desmotadoras de lana, costureras o las que hacían media, tenían rentas muy bajas. En tanto sólo contaban con ese único trabajo, que sin duda está relacionado con la crisis y decadencia de la manufactura textil. Sus ingresos tampoco dependían del número de días que a lo largo del año se dedicasen a su actividad textil. Algo que hacían a tiempo parcial, seguramente a ratos sueltos o de manera intermitente en determinados días desocupados de las tareas domésticas o de las labores en el campo. Se pueden contabilizar desde un mínimo de 50 días al año hasta un máximo de 275 días, pero sus ingresos eran los mismos. En el primer caso su salario era de 0,77 reales al día y en el segundo de 0,14 reales, dependiendo de si en el acuerdo o trato alcanzado se contemplase entregar su producción en menos o más tiempo. Eran, en realidad, pobres de solemnidad, como a algunas de ellas se las clasificaba en las propias fuentes, o en anotaciones al margen realizadas a posteriori de entregar los memoriales correspondientes firmados siempre en su nombre por testigos. Alguna de ellas fue víctima del sistema, como se aprecia en un memorial no dictado y seguramente no aceptado por la declarante, que fue redactado sin su consentimiento:

"Francisca Moedano Ce [calle] horno de Santa Clara Parroq ${ }^{a}$ De St $^{\circ}$ Domingo. // Pobre. // No 2250 // Declaro ser De edad De Veinte y tres años casada con Lucas Martnz [Martínez] Ausente en el Real Servicio, Tiene una hija. // Me Perteneze una terzera parte, De una pieza de tierra que fue Viñas, y es inutil, en el sitio De el Beaterio, que las otras dos Pertenezen una, a fernd ${ }^{\circ}$ [Fernando] Moedano, $z^{\circ}$ [vecino] de la $V^{a}$ [Villa] De cazorla y la otra, a Juan Moedano, ya Difunto y pr [por] su muerte se la ha apropiado, el Colletor [Colector] De la Parroq ${ }^{a}$ De Sn Pablo pr Derechos de Entierro. // Notta [al margen] se omite pr no haverse justificado posesion y propriedad de ella. // Y pr no tener mas vienes, doy la presente en esta Ciudad De Ubeda a 8 de Junio de 1752. // To [Testigo] Juan Manrique” (Úbeda, sig.7950).

Pero las más pobres entre las pobres eran las mujeres que no contaban prácticamente con ninguna fuente de ingresos, como el caso dramático de una viuda con 4 hijos menores que sólo ingresaba como arrendadora de una veinteava parte de una casa 4 reales al año. Otras estaban empleadas a cambio de la comida, como los casos de sirvientas que habían pactado trabajar exclusivamente por su manutención, o se veían obligadas a vivir de limosna.

\section{RENTAS MASCULinas}

Los hombres de Úbeda con rentas más elevadas las percibía los altos cargos de la administración, artesanos especializados y empresarios, como serían los casos de caldereros, mercaderes, horneros con trato de panadería, chocolateros, boticarios, molineros, plateros, arrieros, comerciantes, alfareros, mayordomos o administradores. Las rentas más bajas correspondían a los jóvenes menores de 18 años por trabajos poco especializados y a los hombres que tenían tratos como empleados fijos. Se trataba de los jornaleros del campo y muleros fijos, pastores de diversas categorías, sirvientes en la labor, gañanes, criados, sirvientes externos o que ocupaban empleos a tiempo parcial como eran los músicos, cantores, entonadores, campaneros, o en actividades textiles en desuso como les ocurría a los tejedores de paños y bayetas, que apenas trabajaban entre 50 y 70 días al año y no habían encontrado o al menos no declaraban en sus memoriales otras fuentes de rentas. En ese caso estarían también los jornaleros del campo temporeros, como indicaba uno de ellos: "mi trato es un jornal de quien me quiere llevar a trabajar, no tengo siembra ni cosa de contrato” (Úbeda, sig. 7949).

Por último, también había hombres que tenían tratos de trabajar sólo a cambio de la comida y el vestido. Ejemplos de este tipo los encontramos en lo que tenía acordado un sirviente del convento de San Andrés que trabajaba en el horno y la panadería del mismo, un ganadero de cerda, un gañán de mancera y un huertano empleado en el convento de Carmelitas descalzos, que en este último caso no sólo le proporcionaban la comida como a los demás, sino también la ropa de vestir.

En resumen, de la comparación de los dos casos estudiados se desprende que en Laujar las mujeres obtenían sus principales rentas del sector textil, el comercio, los servicios, el hospedaje y, en último lugar, la agricultura y ganadería. En Úbeda, por el contrario, las mujeres percibían sus rentas del sector servicios, lo que nos da idea de una economía más compleja, como era la actividad comercial en tiendas de especería y mercería o de 
otro tipo y el abastecimiento de chocolate, pan, aceite, azúcar, vino o tabaco, servicios de barbería, tenería y trabajando majando esparto o de criadas, aunque también se mantienen del arrendamiento de derechos de escribanía y del hospedaje. Llama la atención que sólo aparezca una cocinera profesional y que apenas haya mujeres que perciban sus rentas del sector agrario como labradoras y pegujaleras. La crisis de la actividad textil se refleja en las escasas rentas que las mujeres ubetenses conseguían haciendo media, hilando o cosiendo.

Por supuesto, tanto en Laujar como en Úbeda, la remuneración del trabajo femenino estaba muy por debajo del masculino. Un buen ejemplo lo proporciona la manufactura de paños de lana en Laujar, donde según las RG las mujeres trabajadoras como "Josefa Clemente viuda de cinco paños que fabrica a el año tiene de hutilidad cien reales"; "Claudia Masía viuda de dos telares y algun paño que suele echar. Doscientos reales"; "Barbara Lopez de tres paños que fabrica cada año, sesenta reales."; "Josepha Berdu viuda de una prensa que tiene de prensar paños se le considera de hutilidad en cada año ciento y setenta reales"; mientras que un hombre trabajando para su madre y con igual o menor producción de paños obtenía mayores ingresos: "Ignacio González por tres paños que fabrica cada año con su trabajo, y lo que trabaja en casa de su madre Seiscientos reales”.

\section{Conclusiones}

En la Andalucía de mediados del siglo XVIII, los mejores tratos laborales se conseguían en los casos en los que se identificaba profesionalmente a la persona trabajadora. Así se confirma en los casos estudiados de Laujar y Úbeda, cuando se cruzan las rentas anuales percibidas con la identidad laboral que se autoatribuía cada uno en su memorial. Los tratos acordados con las mujeres afectaban a algunas profesiones que también ejercían los hombres, pero había otras muchas actividades laborales en las que no aparecían las mujeres. Los ajustes salariales a los que se llegaba para la misma actividad eran muy inferiores en el caso de las mujeres respecto a los hombres.

Las mujeres y hombres que tenían tratos más desfavorables desde el punto de vista salarial, si no eran pobres de solemnidad, resultaba que se debía a que tenían acuerdos complementarios de pagos en especie que a veces declaraban y otras no los hacían constar. Pero como se comprueba en la industria textil de paños de lana, tanto en Laujar como en Úbeda los tratos reflejaban una remuneración del trabajo femenino muy inferior al masculino.

En el sector agrario-ganadero, los tratos alcanzados afectaban sobre todo a los hombres, aunque se encuentran casos de tratos a estilo majoleros y plantío acordados por mujeres.

En el sector industrial y en el de servicios los tratos afectaban a hombres y mujeres, y se hacían para establecer sobre todo las condiciones de pago en especie o en forma de rentas y salarios anuales, mensuales o diarios que debían percibir.

Todos los hombres en edad de trabajar (10-60 años), y a veces los menores o mayores de esas edades, tienen algún tipo de acuerdo vinculado a una ocupación, independientemente de su estado civil o número de hijos, a no ser que pertenezcan a la nobleza, a la administración o estén impedidos para el trabajo por enfermedad, invalidez o cualquier otra causa. En los casos en que está registrado en las fuentes del Catastro de Ensenada, también cuentan con algún tipo de trato laboral las mujeres solteras menores o mayores de edad y las viudas incluso con más de 60 años también tenían algún acuerdo para realizar actividades remuneradas en especie o dinero, contribuyendo con ello al sostenimiento de sus familias. ${ }^{24}$ A veces, las mujeres pobres de solemnidad no hacían constar ningún tipo de trato; pero en sus memoriales registraban poseer bienes raíces, como tierras o casas u otras fuentes de ingresos.

En definitiva, se confirma la existencia de tratos para realizar un trabajo remunerado entre las mujeres en el sector textil de Andalucía en el siglo XVIII. ${ }^{25}$ Dichos pactos establecían una remuneración del trabajo de tipo monetaria o en especie, principalmente en los que se hacían con familias que tenían niñas para colocar, jóvenes y mujeres a los que se les debía proporcionar el alojamiento y manutención a cambio de su trabajo como 
criadas o sirvientas en las casas donde estaban colocadas, aunque también podían trabajar como hilanderas. Igualmente, se pueden incluir a las que tenían arreglos para trabajar en negocios familiares para el mercado, como podía ser el caso de las que hilaban, hacían encajes o medias en sus casas, o despachaban en una tienda, etc., aunque su situación fuese muy precaria y su nivel de vida bajísimo.

\section{BIBLIOGRAFÍA}

Arias, M. A. (2017). Estrategias matrimoniales y poder territorial en Santiago del Estero, 1695-1756. La Casa López de Velasco Sánchez Zambrano. Trabajos y Comunicaciones, (46), e039. https://doi.org/10.24215/23468971e 039 (consulta marzo 2019).

Arias, M. A. (2018). [Revisión del libro Familias en la tormenta. Tierra, familia y transmisión del patrimonio en el Río de la Plata, siglos XVIII y XIX por C. Contente]. Trabajos y Comunicaciones, (47), e059. https://doi.org/10. 24215/23468971e059 (consultado, marzo 2019).

Atkinson, P. (2012). 'Isn't it time you were finishing?': Women's Labor Force Participation and Childbearing in England, 1860-1920. Feminist Economics, (18), 145-164.

Bartolomé, J. M. \& Pérez Álvarez, M. J. (1999). La familia y los comportamientos familiares familia y tipología familiar; la herencia: la transmisión de los bienes patrimoniales y sus estrategias. En L. M. Rubio (Coord.), La historia de León, Vol. 3. Edad Moderna (pp. 211-220). León: Universidad de León.

Benaul, J. M. (1995). Cambio tecnológico y estructura industrial. Los inicios del sistema de fábrica en la industria pañera catalana, 1815-1835, Revista de Historia Económica, (13), 199-226.

Birriel, M. (2005). Jefaturas de hogar femeninas en la ciudad de Granada (1752). I Caracterización demográfica del hogar. En A. L. Cortés Peña, M. L. López-Guadalupe. \& F. Sánchez-Montes (Coords.), Estudios en homenaje al profesor José Szmolka Clares (pp. 591-604). Granada: Universidad de Granada.

Birriel, M. (2008a). De las familias y los hogares. En M. A. Gálvez \& P. Sánchez Gómez (Coords.), La Granada de Mariana Pineda: lugares, historia y literatura (pp. 67-99). Granada: Universidad de Granada.

Birriel, M. (2008b). El cónyuge supérstite en el derecho hispano. Chronica nova: Revista de historia moderna de la Universidad de Granada, (34), pp. 13-44. (Ejemplar dedicado a: Sobrevivir al cónyuge: viudas y viudedad en la España moderna).

Birriel, M. (2015a). Género y espacio doméstico: la casa rural en el siglo XVIII. En M. E. Díez (Coord.), Arquitectura y mujeres en la bistoria (pp. 305-339). Madrid: Síntesis.

Birriel, M. (2015b). Introducción. Chronica nova: Revista de historia moderna de la Universidad de Granada, (41), 11-12. (Ejemplar dedicado a: Almazaras y olivares en la Edad Moderna).

Birriel, M. (2016a). ¿Un consumo imprescindible? El traje femenino en las Cartas de Capital del Valle de Lecrín (1730-1770). Estudios humanisticos. Historia, (15), 117-136.

Birriel, M. (2016b). Espacio y género en la Edad Moderna. Retos, problemas y logros de la investigación. En C. Martínez et al, Mujeres e historia (pp. 89-120). Valladolid: Universidad de Valladolid.

Birriel, M. (2017a). Introducción. En M. Birriel (Ed.), La(s) casa(s) en la Edad Moderna (pp. 9-21). Zaragoza: Instituto Fernando El Católico.

Birriel, M., (Ed.), (2017b). La(s) casa(s) en la Edad Moderna. Zaragoza: Instituto Fernando El Católico.

Blasco, B. (2017c). Vivir y convivir. Familia y espacio doméstico en la Edad Moderna. En M. Birriel (Ed.), La(s) casa(s) en la Edad Moderna (pp. 65-92). Zaragoza: Instituto Fernando El Católico.

Borderías, C. \& Carrasco, C. (1994). Introducción: las mujeres y el trabajo. Aproximaciones históricas, sociológicas y económicas. En C. Borderías, C. Carrasco \& C. Alemany (Comps.), Las Mujeres y el Trabajo: rupturas conceptuales (pp. 17-109). Barcelona: FUHEM/Icaria.

Borderías, C. \& Gálvez, L. (2014). Cambios y continuidades en las desigualdades de género. Notas para una agenda de investigación. AREAS. Revista Internacional de Ciencias Sociales, (33), 7-15. 
Borderías, C. (2012). La reconstrucción de la actividad femenina en Cataluña circa 1920. Historia Contemporánea, (44), $17-47$.

Borderías, C. (2013). Revisiting Women's Labor Force Participation in Catalonia (1920-36). Feminist Economics, (19), 224-242.

Borderías, C. (2014). Salarios infantiles y presupuestos familiares en la Cataluña obrera (1856-1920). En J. M. Borrás (Ed.), (2014). El trabajo infantil en España (1700-1950) (pp. 371-405). Barcelona: Universitat de Barcelona/ Icaria.

Borderías, C., Pérez\#Fuentes, P. \& Sarasúa, C. (2014). La desigualdad en el consumo familiar. Diferencias de género en la España contemporánea (1850-1930), AREAS. Revista Internacional de Ciencias Sociales, (33), 105-120.

Borrás, J. M. (2012). Tasas de actividad infantil y género en la Cataluña de 1900: estudio de casos de la cuenca del Ter, Historia Contemporánea, (44), 73-108.

Borrás, J. M. (Ed.), (2014). El trabajo infantil en España (1700-1950). Barcelona: Universitat de Barcelona/Icaria.

Boudjaaba, F. \& García González, F. (2014). Travail, structures des ménages et solidarités familiales en Espagne et en France au XVIIIe siècle. En F. Boudjaaba (Dir.), Le travail et la famille en milieu rural: (XVIe-XXe siècle) (pp. 69-92). Rennes: Presses universitaires de Rennes.

Boudjaaba, F. \& García González, F. (2017). Introducción al dossier: El trabajo doméstico y sirviente en la Europa rural (ss. XVI-XIX). Diversidad de modelos regionales y formas de dependencia. Mundo Agrario: Revista de estudios rurales, 18 (39), http://www.scielo.org.ar/scielo.php?script=sci_arttext\&pid=S1515-5994201700030 0001 (consulta marzo 2019).

Burnette, J. (2004). The Wages and Employment of Female Day-Laborers in English Agriculture, 1740-1850. The Economic History Review, (57), 664-690.

Burnette, J. (2008). Gender, Work and Wages in Industrial Revolution Britain. Cambridge: Cambridge University Press.

Campos, C. (1996). Trabajadoras asalariadas y conflictividad social en Málaga, 1914-1923, Departamento de Historia Moderna y Contemporánea de la Universidad de Málaga. Tesis doctoral, 2 tomos.

Campos, C. (2012). Trabajo, empleo y género en Andalucía. En M. D. Ramos (Coord.), Ponencias. Taller. Género en la historiografía andaluza. Balance de resultados y expectativas de investigación (pp. 70-92). Sevilla: Centro de Estudios Andaluces, PN08/12.

Campos, C. (2013). Teorías y realidad laboral de las mujeres en Andalucía. En M. D. Ramos (Coord.), Andaluzas en la historia. Reflexiones sobre politica, trabajo y acción colectiva (pp. 113-138). Sevilla: Centro de Estudios Andaluces.

Campos, C. (2014). La tasa de actividad femenina a mediados del siglo XIX en Andalucía: el caso de Antequera. Investigaciones de Historia Económica - Economic History Research, (10), 191-201.

Carbonell-Esteller, M. \& Gálvez, L. (2014). Género y cuidados: respuestas sociales e institucionales al surgimiento de la sociedad de mercado en el contexto europeo. Areas. Revista Internacional de Ciencias Sociales, (33), 17-32.

Carbonell-Esteller, M. \& Marfany, J. L (2017). Gender, life cycle, and family 'strategies' among the poor: the Barcelona workhouse, 1762-1805. Economic History Review, (70), 810-836. https://portalrecerca.csuc.cat/orcid/0000-00 02-6986-3547/publications.html (consulta marzo 2019).

Carbonell-Esteller, M. (1989). Hecho y representación sobre la desvalorización del trabajo de las mujeres (siglos XVI-XVIII). En Mujeres y hombres en la formación del pensamiento occidental, Vol. 2, Jornadas de Investigación Interdisciplinaria sobre la Mujer (pp. 157-172). Madrid: Universidad Autónoma de Madrid.

Carbonell-Esteller, M. (1990). Las mujeres pobres en el Setecientos. Historia social, (8), 123-134.

Carbonell-Esteller, M. (1994). Género, pobreza y estrategias de supervivencia. Barcelona, siglo XVIII. Revista de Demografía Histórica, (12), 301-316.

Carbonell-Esteller, M. (2002). Microcrédito, familias y hogares. Barcelona a finales del siglo XVIII. Revista de Demografía Histórica, (20), 23-52.

Carbonell-Esteller, M. (2005). Trabajo femenino y economías familiares. En I. Morant (Coord.), Historia de las mujeres en España y América Latina, Vol. 2. El mundo moderno (pp. 237-262). Madrid: Cátedra. 
Carbonell-Esteller, M. (2017). Poverty, family economies and survival strategies in the eighteenth and early nineteenth centuries. A gender approach. In D. Simonton (Ed.), The Routledge History Handbook of Gender and the Urban Experience (pp. 58-70). New York: Routledge, Taylor \& Francis.

Carini, G. F. (2018). “No debemos abdicar de todo lo que ha avanzado la reflexión histórica en aras de la popularidad”: dinámicas historiográficas, relatos y contrarrelatos en España. Una entrevista a Juan Pan-Montojo. Trabajos y Comunicaciones, (47), e050. https://doi.org/10.24215/23468971e050 (consulta marzo 2019).

Caula, E. (2018). Reseña de Ofelia Rey-Castelao y Pablo Cowen (editores) Familias en el Viejo y Nuevo Mundo, Facultad de Humanidades y Ciencias de la Educación, Universidad Nacional de La Plata, (HisMundi), 2017. Trabajos y Comunicaciones, (48), e072. https://doi.org/10.24215/23468971e072.

Del Arco, J. (2002). El Catastro del Marqués de Ensenada en el Archivo Histórico Provincial de Jaén, Boletín del Instituto de Estudios Giennenses (CSIC-CECEL), (180), 19-56.

Flather, A. (2017). Early Modern Gender and Space: a methodological Framework. En M. Birriel (Ed.), La(s) casa(s) en la Edad Moderna (pp. 23-44). Zaragoza: Instituto Fernando El Católico.

Folbre, N. (1991). The unproductive housewife: her evolution in nineteenth-century economic thought. Journal of Women in Culture and Society, (16), 463-484.

Franch, R. (2016). Salario y condiciones de trabajo en la industria de la seda valenciana del siglo XVIII. Obradoiro de historia moderna, (25), 207-242.

García González, F. \& Contente, C. (2017). Introducción. Revista de historiografía (RevHisto), (26), 12-18. (Ejemplar dedicado a: Mujeres al frente del hogar en perspectiva histórica, ss. XVIII-XXI) / García González, F. \& Contente, C. (Eds.).

García González, F. \& Pelegrín, J. A. (2004). En torno al trabajo y al comercio de la lana en las altas tierras del sureste peninsular (1750-1800) estrategias y trayectorias familiares. En L. Ferrer \& J. M. Pérez García (Coords.), Reconstituição de famílias, fogos e estratégias sociais: actas do VI congresso da Associação de Demografia Histórica I Asociación de Demografia Histórica (ADEH) (pp. 221-234). Castelo Branco: Instituto Politécnico de Castelo Branco.

García González, F. (1994). Inmigración profesional y actividad industrial en una comarca de montaña del interior castellano a finales del siglo VXIII. En A. Eiras \& O. Rey-Castelao (Dirs.), I Conferencia Europea de la Comisión Internacional de Demografía Histórica, Vol. 2. (Migraciones internas y medium-distance en la Peninsula Ibérica, 1500-1900) (pp. 727-745). Santiago de Compostela: Xunta de Galicia / Consellería de Educación e Ordenación Universitaria. (Recoge los contenidos presentados a: Comisión Internacional de Demografía Histórica. Conferencia Europea. 1. 1993).

García González, F. (1996). Patrimonio conventual y familia arrendataria. Una aproximación desde el Catastro del Marqués de la Ensenada. En X. Balboa \& L. Fernández Prieto (Coords.), La sociedad rural en la España contemporánea: mercado y patrimonio (pp. 87-106). A Coruña: Edicios do Castro.

García González, F. (1997a). Corral de Calatrava en el siglo XVIII: familia, población y sociedad. En F. Alía \& A. de Juan (Coords.), Centenario del Cardenal Monescillo (1897-1997), Vol. 2, (pp. 83-124). Cuenca: Universidad de Castilla-La Mancha.

García González, F. (1997b). La continuidad del hogar. Familia, trabajo y mediana propiedad en una economía de montaña del Antiguo Régimen. En S. Castillo (Coord.), El trabajo a través de la historia: actas del II ${ }^{o}$ congreso de la Asociación de Historia Social. Córdoba, abril de 1995 (pp. 215-222). Madrid: Centro de Estudios Históricos / Asociación de Historia Social. Congreso (2. 1995. Córdoba).

García González, F. (1997c). Más allá del hogar. Casa, trabajo y propiedad en la Comarca de la Sierra de Alcaraz en el siglo XVIII. En F. Chacón \& L. Ferrer (Coords.), Familia, casa y trabajo: Congreso Internacional Historia de la Familia: Nuevas perspectivas sobre la sociedad europea: Murcia 1994. [3a Sesión] / Seminario Familia y Élite de Poder en el Reino de Murcia. Siglos XV-XIX (pp. 331-344). Murcia: Universidad de Murcia.

García González, F. (1997d). Mujer, hogar y economía familiar desigualdad y adaptación en la sierra de Alcaraz a mediados del siglo XVIII. Hispania: Revista española de historia, 57(195), 115-145. 
García González, F. (1998a). Casa vecindario. Relaciones de parentesco, amistad y vecindad en una ciudad de la España meridional del Antiguo Régimen: Alcaraz en el siglo XVIII. En D. Enciso (Coord.), Casa, vecindario y cultura en el siglo XVIII: memoria del VI Simposio de Historia de las Mentalidades (pp. 35-54). México: Instituto Nacional de Antropología e Historia.

García González, F. (1998b). Introducción. De la tierra a la historia de la familia en la España Meridional. En F. García González (Coord.), Tierra y familia en la España meridional, siglos XIII-XIX: formas de organización doméstica y reproducción social (pp. 9-24). Murcia: Universidad de Murcia.

García González, F. (1998c). Labradores, jornaleros y sirvientes en la sierra: organización doméstica y ciclo de vida (Alcaraz, 1753-1787). En F. García González (Coord.), Tierra y familia en la España meridional, siglos XIII-XIX: formas de organización doméstica y reproducción social (pp. 155-192). Murcia: Universidad de Murcia.

García González, F. (1999). Familia, poder y estrategias de reproducción social en la sierra Castellana del Antiguo Régimen (Alcaraz, siglo XVIII). En F. J. Aranda (Coord.), Poderes “intermedios", poderes "interpuestos": sociedad y oligarquias en la España moderna (pp. 195-226). Ciudad Real: Universidad de Castilla-La Mancha.

García González, F. (2004). El grupo doméstico en la Castilla rural: algunos indicadores a mediados del siglo XVIII en la zona centro-meridional. En F.J. Aranda (Coord.),VII a Reunión Cientifica de la Fundación Española de Historia Moderna, Vol. 2. (El mundo rural en la España moderna), (pp. 153-176). Cuenca: Universidad de Castilla-La Mancha. Fundación Española de Historia Moderna. Reunión Científica (7.2002. Ciudad Real)

García González, F. (2008). Movilidad de la población, mujer y matrimonio en la Castilla Meridional. Las tierras de Albacete en el siglo XVIII. En J. Hernández Borge \& D. L. González Lopo (Coords.), Mujer y emigración: una perspectiva plural: actas del Coloquio Internacional, Santiago de Compostela, 23-24 de noviembre de 2006, (pp. 69-106). Santiago de Compostela: Universidad de Santiago de Compostela.

García González, F. (2011). Las estructuras familiares y su relación con los recursos humanos y económicos. En F. Chacón \& J. Bestard (Coords.), Familias: historia de la sociedad española (del final de la Edad Media a nuestros dias) (pp. 159-254). Madrid: Cátedra.

García González, F. (2012). Criados y movilidad de la población rural en la Castilla interior del siglo XVIII. En M. J. Pérez Álvarez \& A. Martín García (Coords.), Campo y campesinos en la España Moderna: culturas políticas en el mundo hispano, Vol. 2 (pp. 1101-1112). León: Fundación Española de Historia Moderna / Madrid: Centro de Ciencias Humanas y Sociales (CSIC).

García González, F. (2015). Investigar la soledad. Mujeres solas, casa y trayectorias sociales en la Castilla rural del Antiguo Régimen. Obradoiro de historia moderna (24), 141-169. (Ejemplar dedicado a: De la demografía histórica a la historia social de la población).

García González, F. (2016a). Introducción. Curso de vida y reproducción social en España y en Europa en la Edad Moderna. Revista de historia moderna: Anales de la Universidad de Alicante, (34), 15-21. (Ejemplar dedicado a: Curso de vida y reproducción social en España y en Europa en la Edad Moderna).

García González, F. (2016b). Vejez, viudedad y soledad rural. Viudas, hogares y prácticas familiares en la España centro-meridional del siglo XVIII. Studia historica. Historia moderna (38), 287-324. (Ejemplar dedicado a: Crisis familiares y curso de vida en la España Moderna).

García González, F. (2017a). Mujeres al frente de sus hogares. Soledad y mundo rural en la España interior del Antiguo Régimen. Revista de historiografía (RevHisto) (26), 19-46. (Ejemplar dedicado a: Mujeres al frente del hogar en perspectiva histórica, ss. XVIII-XXI / García González, F. \& Contente, C. (Eds.).

García González, F. (2017b). Sirvientes y criados en el mundo rural de la España interior, 1700-1860. Desigualdad social y dependencia. Mundo Agrario: Revista de estudios rurales 18(39). http://www.scielo.org.ar/scielo.php?sc ript $=$ sci_arttext\&pid $=$ S1515-59942017000300009 (consulta marzo 2019).

García González, F. (Coord.), (1998). Tierra y familia en la España meridional, siglos XIII-XIX: formas de organización doméstica y reproducción social. Murcia: Universidad de Murcia.

Garrido-González, L. (1996). Orígenes de la moderna infraestructura viaria andaluza en el siglo XVIII. En Actas del vii Congreso sobre Andalucismo Histórico. Jaén, 28-30 de septiembre de 1995 (pp. 363-375). Sevilla: Fundación Blas Infante. 
Garrido-González, L. (2011). Tasa de actividad femenina registrada en Jaén en el siglo XVIII. El caso de Úbeda. En $X$ Congreso Internacional de la AEHE Carmona (Sevilla), 8-9 septiembre 2011. Sevilla: Universidad Pablo de Olavide.

Garrido-González, L. (2013). Reconstrucción de la Tasa de Actividad Femenina registrada en Laujar de Andarax (Almería), 1751 y Úbeda (Jaén), 1752. En X Congreso Internacional de la ADEH, 18-21 de junio de 2013. Albacete: Universidad Castilla-La Mancha.

González Enciso, A. (1998). Los gremios y el crecimiento económico. Memoria y Civilización, (1), 111-137.

Hernández, R. (2013). Women's Labor Participation Rates in the Kingdom of Castilla in the Eighteenth Century. Feminist Economics (19), 181-199.

Horrell, S. \& Humphries, J. (1995). Women's labour force participation and the transition to the male-breadwinner family, 1790-1865. The Economic History Review (48), pp. 89-117.

Horrell, S. \& Humphries, J. (1997). The Origins and Expansion of the Male Breadwinner Family: The Case of Nineteenth-Century Britain. International Review of Social History, 42(supplement S5), 25-64.

Humphries, J. \& Sarasúa, C. (2012). Off the record: reconstructing women's labor force participation in the European past. Feminist Economics, (18), 39-67.

Humphries, J. \& Weisdorf, J. (2014). The Wages of Women in England, 1260-1850. Oxford Economic and Social History Working Papers (Ref: Number 127), 43 págs.

Humphries, J. (2010). Childhood and Child Labour in the British Industrial Revolution. Cambridge: Cambridge University Press.

Humphries, J. (2013). The lure of aggregates and the pitfalls of the patriarchal perspective: a critique of the high wage economy interpretation of the British industrial revolution. Economic History Review, (66), 693-714.

Jaciuk, M. B. (2017). La sociedad porteña y sus conformaciones familiares. Fines del siglo XVIII y principios del XIX. Trabajos y Comunicaciones (45), e036. https://doi.org/10.24215/TyCe036 (consulta marzo 2019).

López Ontiveros, A. (1999). El catastro de Ensenada y las medidas de tierra en Andalucía. Revista de Estudios Regionales, (53), 191-204.

López-Cordón, M. V. \& Carbonell-Esteller, M. (1997). Mujer, familia y matrimonio. En M. V. López-Cordón, \& M. Carbonell-Esteller (Dirs.), Historia de la mujer e historia del matrimonio: Congreso Internacional Historia de la Familia: Nuevas perspectivas sobre la sociedad europea: Murcia 1994. [2ª Sesión] / Seminario Familia y Élite de Poder en el Reino de Murcia. Siglos XV-XIX, (pp. 13-22). Murcia: Universidad de Murcia.

Madoz, P. (1850a). Diccionario geográfico, estadístico, histórico de España y sus posesiones de ultramar 1845-1850. Almería. Valladolid: Ámbito ediciones, 1988.

Madoz, P. (1850b). Diccionario geográfico, estadístico, histórico de España y sus posesiones de ultramar1845-1850. Jaén. Valladolid: Ámbito ediciones, 1988.

Martín García, A. \& Pérez Álvarez, M. J. (2014). Estrategias de reproducción social de la élite de la ciudad de León en la Edad Moderna. En F. Chacón (Coord.) \& C. J. Gómez Carrasco (Comp.), Familias, recursos humanos y vida material (pp. 427-446). Murcia: Universidad de Murcia.

Martínez López, D. \& Martínez Martín, M. (2003). El trabajo femenino y la economía campesina de subsistencia en Andalucía: las hilanderas de Montefrío. En C. Sarasúa \& L. Gálvez (Eds.), ¿Privilegios o eficiencia? Mujeres y hombres en los mercados de trabajo (pp. 137-156). Alicante: Universidad de Alicante.

Mayo, C. A. (1996). La pulpería como empresa en Buenos Aires (1740-1830). Trabajos y Comunicaciones (24). http: //www.trabajosycomunicaciones.fahce.unlp.edu.ar (consulta marzo 2019).

Mayordomo, M. (2000). Precursores: el trabajo de las mujeres y la Economía Política. VIIJornadas de Economía Critica, 3-5 febrero 2000. Albacete: Universidad de Castilla-La Mancha, CD.

Menéndez González, A. (1990). Asturias y el comercio con América en el siglo XVIII. Boletín del Real Instituto de Estudios Asturianos, 44(135), 541-590.

Menéndez González, A. (1997). La industria experimental en la crisis del antiguo régimen. La fábrica nacional de Fontameña (Parres), 1804-1823. Boletín del Real Instituto de Estudios Asturianos, 51(150), 173-186. 
Molinari, I. D. (2008). Obreras, operarias y empleadas. El trabajo de las mujeres en Mar del Plata, entre los años 1940 y 1960. Trabajosy Comunicaciones (34). http://www.trabajosycomunicaciones.fahce.unlp.edu.ar (consulta marzo 2019).

Muñoz Abeledo, L. (2010). Género, trabajo y niveles de vida en la industria conservera de Galicia (1870-1970). Barcelona: Universitat de Barcelona/Icaria.

Muñoz Abeledo, L. (2012a). Women in the Rural and Industrial Labor Force in Nineteenth Century Spain. Feminist Economics, (18), 121-143.

Muñoz Abeledo, L. (2012b). Actividad femenina en industrias pesqueras de España y Portugal (1870-1930). Historia Contemporánea, (44), 49-71.

Muñoz Abeledo, L., Taboada, S. \& Verdugo, R. (2013). Ciclo vital y mercado laboral en la Galicia del siglo XIX: actividad femenina y condicionantes de oferta. X Congreso Internacional de la ADEH, 18-21 de junio de 2013 (pp. 1-14). Albacete: Universidad de Castilla-La Mancha.

Ogilvie, S. (2019). The European Guilds: An Economic Analysis. Princeton, New Jersey: Princeton University Press.

Parejo, A. (1987). Industria dispersa e industrialización en Andalucía. El textil antequerano (1750-1900). Málaga: Universidad de Málaga.

Pérez Álvarez, M. J. (1997). Estructura de la familia en los ancares leoneses resultado de unas estrategias sucesorias. En F. Chacón \& L. Ferrer (Coords.), Familia, casa y trabajo: Congreso Internacional Historia de la Familia: Nuevas perspectivas sobre la sociedad europea: Murcia 1994. [3ª Sesión] / Seminario Familia y Élite de Poder en el Reino de Murcia. Siglos XV-XIX (pp. 255-260). Murcia: Universidad de Murcia.

Pérez Álvarez, M.J. (2014). Modelos femeninos en la sociedad española del Antiguo Régimen. en O. Fernández Álvarez (Coord.), Mujeres en riesgo de exclusión social y violencia de género, (pp. 435-448). León: Universidad de León.

Pérez Álvarez, M. J. (2016). Mujeres, familia y sociedad en la montaña leonesa en el siglo XVIII. En M. R. García Hurtado (Coord.), El siglo XVIII en femenino (pp. 191-218). Madrid: Síntesis.

Pérez-Fuentes, Pilar (2013). Women's Economic Participation on the Eve of Industrialization: Bizkaia, Spain, 1825. Feminist Economics, (19), 160-180.

Puertas, A. (1991). Laujar de Andarax en el siglo XVIII. Almería: Instituto de Estudios Almerienses / Ayuntamiento de Laujar de Andarax.

Rey-Castelao, O. \& Rial, S. M. (2009). Historia de las mujeres en Galicia (siglos XVI al XIX). Vigo: Nigratea.

Rey-Castelao, O. (1993). Las economías monásticas femeninas ante la crisis del Antiguo Régimen. En M. I. Viforcos \& J. Paniagua Pérez (Coord.), I Congreso Internacional del Monacato Femenino en España, Portugal y América, 1492-1992, Vol. 2 (pp. 105-130). León: Universidad de León. Recoge los contenidos presentados al: Congreso Internacional del Monacato Femenino en España, Portugal y América, 1492-1992 (1. 1992. León)

Rey-Castelao, O. (1994). Mujer y sociedad en la Galicia del Antiguo Régimen. Obradoiro de historia moderna, (3), 51-70.

Rey-Castelao, O. (2005). Mujeres en la economía campesina. En Morant, I. (Coord.), Historia de las mujeres en España y América Latina, Vol. 2. El mundo moderno (pp. 263-286). Madrid: Cátedra.

Rey-Castelao, O. (2006). Les femmes 'Seules' du Nord-Ouest de l'Espagne, trajectoires féminines dans un territoire d'emigration 1700-1860. Annales de démographie historique, (2), 105-134.

Rey-Castelao, O. (2008). Las migraciones femeninas de Antiguo Régimen en su contexto europeo. En J. Hernández \& D. L. González Lopo (Coords.), Mujer y emigración: una perspectiva plural: actas del Coloquio Internacional, Santiago de Compostela, 23-24 de noviembre de 2006 (pp. 39-68). Santiago de Compostela: Universidade de Santiago de Compostela.

Rey-Castelao, O. (2009a). El servicio doméstico del clero regular gallego a fines de la edad Moderna. En R. Casal, J. M. Andrade \& R. J. López (Coords.), Galicia monástica: estudos en lembranza da profesora María José Portela Silva (pp. 289-310). Santiago de Compostela: Universidade de Santiago de Compostela. 
Rey-Castelao, O. (2009b). VI. Las economías monásticas femeninas: un estado de la cuestión. En C. Borderías (Ed.), La historia de las mujeres: Perspectivas actuales (pp. 197-224). Barcelona: Asociación Española de Investigación de Historia de las Mujeres (AEIHM)/Icaria.

Rey-Castelao, O. (2010). Trabajando a cubierto: las empleadas institucionales a fines del Antiguo Régimen. Mélanges de la Casa de Velázquez, (40), 73-93. (Ejemplar dedicado a: Le travail des femmes en Espagne de l'Antiquité au XXe siècle).

Rey-Castelao, O. (2012a). Las mujeres en la Galicia moderna: lo que sabemos y no sabemos de ellas. En M. GarcíaFernández, S. Cernadas \& A. Ballesteros (Coords.), As mulleres na historia de Galicia, Vol. 1 (pp. 117-139). Santiago de Compostela: Andavira.

Rey-Castelao, O. (2012b). Mujeres, trabajo y migraciones urbanas en España durante la segunda mitad del siglo XVIII. Revista de historiografía (RevHisto) (16), 44-60. (Ejemplar dedicado a: La Ciudad y la construcción de la modernidad).

Rey-Castelao, O. (2015). El trabajo de las mujeres rurales en la España Moderna. Un balance historiográfico, 1994/2013. Revista de historiografia (RevHisto) (22), 183-210. (Ejemplar dedicado a: Del ayer al mañana. La historiografía de la historia de las mujeres, del género y del feminismo).

Rey-Castelao, O. (2018). Reseña de Gloria Franco Rubio, El ámbito doméstico en el antiguo régimen, Madrid. Chronica nova: Revista de historia moderna de la Universidad de Granada, (44), 470-473.

Rial, S. M. \& Rey-Castelao, O. (2008). Las viudas de Galicia a fines del Antiguo Régimen. Chronica nova: Revista de historia moderna de la Universidad de Granada, (34), 91-122. (Ejemplar dedicado a: Sobrevivir al cónyuge: viudas y viudedad en la España moderna).

Rial, S. M. (1993). Las mujeres en la economía urbana compostelana del siglo XVIII. Conclusiones y su ejemplificación en las actividades comerciales. Obradoiro de historia moderna, (2), 173-184.

Rial, S. M. (1994). La actuación de las mujeres de ausentes en el comercio de bienes raíces en el entorno de la tierra de Santiago, 1700-1840. En A. Eiras \& O. Rey-Castelao (Dirs), I Conferencia Europea de la Comisión Internacional de Demografia Histórica, Vol. 2, 1994 (Migraciones internas y medium-distance en la Peninsula Ibérica, 1500-1900) (pp. 499-515). (Recoge los contenidos presentados a: Comisión Internacional de Demografía Histórica. Conferencia Europea. 1. 1993). Santiago de Compostela: Xunta de Galicia / Consellería de Educación e Ordenación Universitaria.

Rial, S. M. (1995). Las mujeres en la economia urbana del antiguo régimen. Santiago durante el siglo XVIII. La Coruña: Ediciós do Castro.

Rial, S. M. (1999). Las mujeres solas en la sociedad semi-urbana gallega del siglo XVIII. Obradoiro de historia moderna, (8), 169-197.

Rial, S. M. (2003a). Las mujeres, el trabajo y la familia en la Galicia moderna. Obradoiro de historia moderna, (12), 189-221.

Rial, S. M. (2003b). Mujer y actividad económica en la Galicia moderna: la inserción de las mujeres en la producción económica rural y urbana. Tesis doctoral, Universidade de Santiago de Compostela.

Rial, S. M. (2005a). El trabajo de las mujeres del campo en la Galicia moderna. Madrid: Asociación Española de Investigación de Historia de las Mujeres (AEIHM).

Rial, S. M. (2005b). Las mujeres de las comunidades maritimas de Galicia durante la época moderna. Una biografía colectiva. (Obra ganadora de la XIII Edición del Premio de Investigación María Isidra de Guzmán, año 2004, convocado por el Excmo. Ayuntamiento de Alcalá de Henares.) Alcalá de Henares (Madrid): Ayuntamiento de Alcalá de Henares.

Rial, S. M. (2005c). Solas y pobres. Las mujeres de las ciudades de Galicia ante la marginalidad y la prostitución. Semata: Ciencias sociais e humanidades, (16), 301-332.

Rial, S. M. (2006). El trabajo de las mujeres del campo y la economía familiar en la Galicia Moderna. Arenal: Revista de historia de mujeres (13), 7-37. (Ejemplar dedicado a: La familia en la Edad Moderna). 
Rial, S. M. (2008). Una mirada a la evolución historiográfica de la historia de las mujeres. Semata: Ciencias sociais e humanidades, (20), 155-188. (Ejemplar dedicado a: En femenino: voces, miradas, territorios / coord. por M. Villarino, O. Rey-Castelao \& R. Sánchez Ameijeiras).

Rial, S. M. (2009). Trabajo femenino y economía de subsistencia. El ejemplo de la Galicia moderna. Manuscrits: Revista d'història moderna, (27), 77-99.

Ros, R. (1998). Gremios y empresas en la industria lanera de Béjar, 1680-1808. Revista de Historia Industrial, (13), 11-35.

Sandrín, M. E. (2018). La región Río de la Plata como articuladora de demandas que dinamizaron su economía en el largo siglo XVIII (1680-1810). Trabajos y Comunicaciones (48), e071. https://doi.org/10.24215/23468971e0 71 (consulta marzo 2019)

Sarasúa, C. \& Gálvez, L. (2003). Mujeres y hombres en los mercados de trabajo ¿Privilegios o eficiencia? En C. Sarasúa \& L. Gálvez (Eds.), ¿Privilegios o eficiencia? Mujeres y hombres en los mercados de trabajo (pp. 9-33). Alicante: Universidad de Alicante.

Sarasúa, C. \& Gálvez, L. (Eds.), (2003). ¿Privilegios o eficiencia? Mujeres y hombres en los mercados de trabajo. Alicante: Universidad de Alicante.

Sarasúa, C. (2007). Trabajo y trabajadores en la España del siglo XIX. En A. González Enciso \& J. M. Matés (Coords.), Historia económica de España (pp. 413-433). Barcelona: Ariel.

Schmidt, A. \& Nederveen Meerkerk, E. (2012), Reconsidering the 'first male breadwinner economy': long-term trends in female labour force participation in the Netherlands, c. 1600-1900. Feminist economics, (18), 69-96.

Tarifa, A. (1999). Breve historia de Úbeda. Málaga: Sarriá.

Thomas, J. (1988). Women and Capitalism: Oppression or Emancipation? A review article. Comparatives Studies in Society and History, (30), 534-549.

Tilly, L. A. \& Scott, J. W. (1989). Women, work, and family. New York / London: Routledge.

Torras, J. (1981). Estructura de la indústria pre-capitalista. La draperia. Recerques: História, economia i cultura, (11), 7-28.

Torras, J. (1985). La industria precapitalista y las tesis sobre la protoindustrialización. En Industrialización y nacionalismo: análisis comparativo. Actas del I Coloquio Vasco-Catalán de Historia celebrado en Sitges, 20-22 de diciembre de 1982 (pp. 63-72). Barcelona: Universitat Autònoma de Barcelona.

Valiente, A. (2014). Economía e industria textil en la España Moderna: el arte mayor de la seda de Écija. Sevilla: Universidad de Sevilla.

Van Nederveen Meerkerk, E. \& Schmidt, A. (2008). Between Wage Labour and Vocation: Child Labor in Dutch Urban Industry, 1600-1800. Journal of Social History, (41), 717-736.

Van Nederveen Meerkerk, E. (2007). De draad in eigen handen Vrouwen en loonarbeid in de Nederlandse textielnijverheid, 1581-1810, Vrije Universiteit Amsterdam (Tesis doctoral). https://www.academia.edu/1495106/De_draad_in_eigen_handen._Vrouwen_en_loonarbeid_in_ de_Nederlandse_textielnijverheid_1581-1810 (consulta marzo 2019).

Van Nederveen Meerkerk, E. (2008). Counting women in. Female labour market participation in the Dutch textile industry, c. 1600-1800. En 14th Berkshire Conference on the History of Women, Minneapolis, 12-15 June 2008, 19 págs.

Van Nederveen Meerkerk, E. (2013). Industriousness in an imperial economy. Delineating new research on colonial connections and household Labour relations in the Netherlands and the Netherlands Indies. En Workers of the World: International Journal on Strikes and Social Conflicts (pp. 102-117). Cornell University ILR School, 1(3), May 2013. 


\section{Notas}

1 Este trabajo se ha realizado dentro del Proyecto de Investigación HAR2009-11709 (subprograma HIST). Una versión preliminar se sometió a debate en las XV Jornadas de Historia del Trabajo, celebradas en la Facultad de Geografía e Historia de la Universidad de Barcelona (España) el 4 y 5 de junio de 2015. Agradezco las sugerencias recibidas en las mismas, así como los cometarios de Carmen Sarasúa y Cristina Borderías. Los datos primarios se pueden ver en los anexos del Documento de Trabajo de la Asociación Española de Historia Económica DT-AEHE N¹612 (https://www.aeh e.es). Finalmente, quiero agradecer a los evaluadores anónimos de la Revista Trabajos y Comunicaciones, sus consejos y críticas que han contribuido a mejorar el resultado final, del cual soy el único responsable.

2 Carbonell-Esteller y Marfany (2017). Carbonell-Esteller (1990, 1994, 2005, 2017). García González (1997c, 1997d). Humphries y Sarasúa (2012). Borderías, Pérez\#Fuentes y Sarasúa (2014a, 2014b). Para Holanda, van Nederveen (2007). Schmidt y van Nederveen (2012). van Nederveen y Schmidt (2008). Para Inglaterra, Burnette (2004), (2008). Atkinson (2012). Humphries y Weisdorf (2014). Para Cataluña, Borderías (2012), (2013), (2014). Borrás (2012). Borrás (ed.) (2014). Para el País Vasco en Pérez-Fuentes (2013). Para Andalucía en Parejo (1987). Campos (1996, 2012 , 2013, 2014). Martínez López y Martínez Martín (2003). Garrido (2011, 2013). Valiente (2014). Para Castilla-León Hernández (2013). La presencia de mujeres responsables de las pequeñas empresas de pulperías porteñas, está constatada a partir de 1740, en Mayo (1996), si bien eran siempre viudas o hijas del dueño en el Buenos Aires colonial. Véase el caso de las viudas en Galicia, Rial y Rey-Castelao (2008), y el papel de las mujeres en la economía urbana compostelana, Rial (1993, 1994, 1995, 1999, 2003a, 2003b). Pero hay que tener en cuente que, como se ha demostrado en González Enciso (1998), Ros (1998) y Ogilvie (2019), el sistema gremial imponía unas barreras de entrada y una política discriminatoria respecto de las mujeres y otra serie de grupos religiosos y étnicos; de tal manera que los gremios siempre actuaron para excluir a las mujeres, aparte de restringir la pertenencia al mismo, monopolizar la producción, la explotación de los proveedores y la mano de obra contratada. En el caso de Galicia, los trabajos de Muñoz Abeledo (2010, 2012a, 2012b), Muñoz Abeledo, Taboada y Verdugo (2013), para períodos posteriores al aquí estudiado explican que la actividad laboral femenina en la industria conservera no era remunerada durante todo el año.

3 Para una ampliación y desarrollo de estas cuestiones, véase en Romero (2010).

4 Archivo Histórico Provincial de Almería, Laujar de Andarax, 1751, signaturas 43640, 43641 y 43642.

5 Archivo Histórico Provincial de Jaén, Catastro de Ensenada, Úbeda, 1752, signaturas 7939, 7940, 7941, 7942, 7943, 7944, 7945, 7946, 7947, 7948, 7949, 7950, 7951, 7952, 7953, 7954.

6 Tilly y Scott (1989). Ya sea por la falta de atención que los censos prestaban al trabajo y a la situación laboral de las mujeres (Folbre, 1991) o porque el tipo de trabajo que estas realizaban no se registraba en las categorías censales (Horrell y Humphries, 1995), los censos han tendido a subestimar el empleo femenino, aunque la documentación sobre el trabajo femenino en el siglo XVIII, en realidad, es inabarcable, comolo demuestra la investigación en los protocolos notariales (contratos, poderes, etc.) o en los pleitos (se cuentan por cientos los de impagos de salarios de criadas, costureras, etc.), que son unas fuentes que no tienen los problemas de una fuente fiscal con una fortísima ocultación como es el Catastro de Ensenada. De hecho, se ha calculado que los salarios rebajan la realidad hasta un $50 \%$, en especial el referido a las mujeres y a las actividades que no salían a la luz, porque es seguro que había muchas más hilanderas que las que constan en las listas personales, servicio doméstico por horas, como era propio de los núcleos semiurbanos, o las tareas realizadas en los recursos comunales disponibles en cada comunidad.

7 Algo sobre lo que se llama la atención en Carini (2018: 5), en la entrevista realizada a Juan Pan-Montojo, donde dice: “Además, considero que el género está aquí para quedarse no tanto como especialidad en sí, aunque también, sino para teñir nuestro acercamiento a todos los demás objetos. De forma que el género va a ser una lente de nuestra forma de apreciación de la política del pasado no tanto por la ausencia muy presente de las mujeres en el espacio público cuanto por el recurso a las propias categorías de masculinidad y de feminidad para entender a los actores". Véase también en la reseña de Caula (2018) al libro de Ofelia Rey-Castelao y Pablo Cowen (Eds.), Familias en el Viejo y Nuevo Mundo, Facultad de Humanidades y Ciencias de la Educación, Universidad Nacional de La Plata, (HisMundi), 2017. Véase también la evolución de la historiografía de la historia de las mujeres en Carbonell-Esteller (1989). Rial (2008), ReyCastelao (2015) y Birriel (2016b). Flather (2017). García González y Contente (2017).

8 Se han consultado todas las relaciones de las 74 localidades de las que se conserva el Catastro de Ensenada en la provincia de Jaén, y sólo en el caso de Úbeda se da información del trabajo femenino. Arco (2002). Para Almería se ha realizado un muestreo de 8 localidades: Berja, Dalias, Laujar de Andarax, Loroya, Olula de Castro, Olula del Río, Presidio y Vera, de cuya consulta ha resultado que únicamente en Laujar había información del trabajo de las mujeres. También quiero agradecer a la profesora Concepción Camarero la información para su localización.

9 La industria antes de la industrialización en Torras (1985, pp. 63-72), y para el caso andaluz en Parejo (1987, pp. 65-157).

10 Rasgos que compartía con otras zonas catalanas, Torras (1981). 
11 En el Catastro de Ensenada de Antequera en 1752, sólo se registran "un total de 798 individuos empleados en la industria lanera -sin contemplar el trabajo femenino e infantil-”, igual que sucede con las industrias sedera y linera, véase Parejo, 1987, pp. 208, 247.

12 Un ejemplo es el de Miguel de la Torre de 31 años casado con Rosa María Raya sin hijos, que en su memorial se califica como jornalero del campo, pero posee 2 celemines de tierra con 169 vides y "Estoi Plantando de Viña Una pieza de tierra ppropia de Dn Juan de Narbaez [...] consiste, en seís cuerdas Siete zelemis [celemines] y medio de tierra, con el plantio de quatromil Vides; y faltan pr [por] Dos cuerdas que se a de partir, cumplidos los nueve años a estilo de maxoleros, pa [para] lo que ban corridos tres". Úbeda, sig.7948. El propietario con el que se había llegado a esa especie de aparcería era D. Juan Clemente Chirino Narváez Mesía y Berrio, caballero hijodalgo notorio, señor de la villa de Grañena la vieja y regidor perpetuo de Úbeda.

13 Véanse los datos primarios en que se basa el presente trabajo en las Tablas A1 y A2 para Laujar y A3 y A4 para Úbeda, en DT-AEHE No1612 (https://www.aehe.es).

14 Además, normalmente, las remuneraciones de los criados no suelen aparecer, porque trabajaban a cambio de la comida, alojamiento o vestido, en especial en el caso de niños y mujeres.

15 A los hombres también les ocurría. Por ejemplo, en Úbeda, Beltrán Bernabé que era el cochero mayor del Conde de Guadiana declaraba en su memorial que "Tengo de Salario por razón de dicho mi ejercicio 30 rs cada mes y cada día 3 libras de Pan y una de carne”. Úbeda, sig. 7950. El casero de la casería de Na Sa de Guadalupe, Basilio Aguirre decía: "Declaro que como casero de dicha casería tengo de salario anual doze Ducados, y ocho fs [fanegas] de trigo. Gratificación pr [por] tal casero. Asimismo tengo tierra del mismo Santuario de cavida de tres cdas [cuerdas] q [que] produce un fruto con un año de yntermo [intermedio] de trigo y zeva [cebada], sin pagar renta alguna. También tengo de salario dos@ de Azeite $\mathrm{p}^{\mathrm{a}}$ [para] mi gasto". Úbeda, sig. 7950.

16 Como demostraron Tilly y Scott (1989) para los casos de Francia e Inglaterra, los empleos con que se cantaban eran limitados y estaban segregados por género, la mayoría los ocupaban mujeres jóvenes y solteras relacionados con las manufacturas familiares características de la protoindustria o putting-out-system, los talleres a pequeña escala, el comercio y los servicios.

17 Pegujalero casado con un hijo mayor de 18 años y otro menor que trabajaban sus tierras, y dos hijas mayores de 18 años sobre las que no se anota ninguna ocupación, aunque junto con su madre debían realizar las tareas domésticas.

18 En los casos que se daban en ducados, la equivalencia es de 11 rs un ducado. La renta en especie se pagaba en fanegas de trigo con una equivalencia de 15 rs/fg, arrobas de aceite a 13 rs/@, arrobas de vino a 1 rs/@, cerdos de 8 arrobas a 20 rs/cerdo y en fanegas de tierra a pegujal para sembrar trigo a $90 \mathrm{rs} / \mathrm{fg}$. Por ejemplo, Juan Raya, un gañán de 44 años que trabajaba para el presbítero de Úbeda, D. Rodrigo Nava, declaraba: "Tengo de salario pr [por] tal Gañan diez y seis ducados y fanega y ma [media] de Peujar [pegujal] pr el tpo [tiempo] de estibo [estival, verano]" (Úbeda, sig. 7947). Sebastián Pomares, un mulero de 48 años que trabajaba para el convento de S. Andrés: "gana veinte y quatro ducados por año, y dos fanegas de peujar [pegujal] que se le costea en un todo” (Úbeda, sig. 7940). Por último, Bartolomé López, pastor mayoral del ganado del Hospital de Santiago "donde tengo mi habitaon [habitación] Declaro estar en edad de quarenta y seis años Casado, y q mi familia se compone seis hijos menores de 18 años y tres hijas. Por Pastor maioral tengo de salario once mil doscientos y veinte mrs [maravedíes] qe [que] hacen trescientos y treinta rs Y diez y ocho fnas [fanegas] de trigo. Ganado de trato ochenta carneros" (Úbeda, sig. 7948).

19 La "utilidad" se denominaba también "se utiliza", y se revisaba hasta en los casos en que en el memorial se expresaba explícitamente que "merece ganar de utilidad por su arriendo o arrendamiento" o "cuando ha estado alquilada ha ganado" una determinada cantidad.

20 A título de ejemplo, respecto a la manufactura textil de Laujar, las RG hacían constar de "los Jornaleros que se ocupan en la fabrica de Lanas, y en la hilatura de seda que quedan muy pocos, y hacen Juicio seran hasta Quarenta, y que el Jornal que regularmente ganan en cada un Dia son tres reales, y que considerando las temporadas que estos trabajan del año hacen Juicio que serán cien Días". En Úbeda, un jornalero agrícola típico era Juan Martínez de 37 años, casado con una mujer de 35 con dos hijos menores, sin que indique el nombre de su esposa, que declara ser propietario de media casa "y no tengo más trato comercio ni ejercicio que trabaxar en las labores q [que] a su tiempo ofrece el campo que comunmente llaman Jornaleros”. Un caso distinto es el del oficial cantero José García de 43 años casado con Ana María Corrales y dos hijos, que declara una "utilidad de 100 ducados [1.100 rs año] al año, por no ser el trabajo continuado", Úbeda, sig. 7949. Otro el del maestro de albañilería Cristóbal Ruiz de 56 años, casado con María Sampedro Peñas, viviendo con una sobrina mayor de 18 años que debía hacer las labores doméstica, que decía: "mi oficio me da de utilidad el día que trabajo tres Rs y mo [3,5 rs]”, Úbeda, sig. 7948. Aunque otros sí ingresan todos los días del año como le ocurría al pastor zagal Manuel Jesús Martínez de 24 años, casado con Felipa Alvarado sin hijos: “y me dan de Salario por mi trabajo veinte y zinco rs. p. mes”, es decir, unos 300 rs por año y 0,82 rs al día, Úbeda, sig. 7949.

21 Los datos de rentas anuales de Laujar para mujeres y hombres, que son los únicos que aporta la fuente, sin que se conozca el número de días de trabajo al año, con la excepción de los jornaleros en fábrica de lanas y en hilatura de seda que trabajan por temporadas al año de 100 días, se reproducen en las tablas A1 y A2 incluidas en el anexo del documento de trabajo 
DT-AEHE No1612 (https://www.aehe.es). En las tablas A3 y A4 del anexo del mismo documento, se registran las rentas anuales de mujeres y hombres de Úbeda, donde a pesar de que en algunos casos se hace mención a los días trabajados, se ha optado por no incluirlos al ser muy fragmentarios y no existir seguridad de que fuesen realmente los declarados.

22 La barchela era una medida de tierra que sólo se utilizaba en Laujar de Andarax y que podía equivaler a un celemín, según López Ontiveros (1999, p. 201).

23 Una hortelana pegujalera de Úbeda tenía un trato para plantar estacas de olivar del tipo majolero: "que se a de partir cumplidos los nueve aos [años] a estilo de Majoleros para los que ban corridos quatro" (Úbeda, sig. 7947). Otro ejemplo de trato frecuente era el de una viuda propietaria de tierras de cultivo, que decía: "Relacíon que yo María de el Villar [...] doi [...] en la forma sigte. Primeramente declaro estar en edad sesenta y dos años y componerse mi famílía de un ijo mayor de diez y ocho años el que se exercita en cuidar de mi hacienda, y dos ijas de la misma edad y una moza de mayor edad la que se ocupa en el aseo de mi casa la que me gana diez ducados [110 rs], y quatro mozos tres maiores de diez y ocho años y uno menor los que me ganan zien ducados [1.100 rs] anuales y se exerzitan en labrar mis posesiones" (Úbeda, sig. 7947).

24 Sobre la importancia de las mujeres viudas como cabezas de familia en la ciudad de Granada, Birriel (2005, 2008a, 2008b). Más en general, Boudjaaba y García González (2014). Para Barcelona, Carbonell-Esteller (1994, 2002, 2005, 2017). Para el caso de Alcaraz en Castilla-La Mancha, García González (1997a, 1997b, 1997c, 1997d, 1998a, 1998c, 1999). Más en general para la zona centro y meridional de Castilla-La Mancha, García González, F. (2004, 2011, 2015 , 2016b, 2017a). Para una comparación con el conjunto de España y Europa, García González, F. (2016a). Para el caso de León, Pérez Álvarez (2014, 2016). Para Galicia, Rey-Castelao, O. (1994, 2005, 2006, 2009a, 2010). Rial y Rey-Castelao (2008). Rial (1994, 1995, 1999, 2003a, 2003b, 2005a, 2005b, 2005c, 2006, 2009).

25 Se puede comparar con el caso de la industria textil de la seda en Écija (Sevilla), Valiente (2014). Con el textil catalán precapitalista, Torras (1981), o con la industria de la seda valenciana del siglo XVIII, Franch, R. (2016). 